\title{
Predicting the mass spectra of environmental pollutants using computational chemistry: a case study and critical evaluation
}

Sophia A. Schreckenbach ${ }^{1}$, James S. M. Anderson², Jeroen Koopman ${ }^{3}$, Stefan Grimme Myrna J. Simpson ${ }^{1}$ and Karl J. Jobst ${ }^{4 *}$

${ }^{1}$ Departments of Chemistry and Physical and Environmental Sciences, University of Toronto, Toronto, ON, MIC 1A4, Canada ${ }^{2}$ Institute of Chemistry, Universidad Nacional Autónoma de México, Mexico City, 04510, Mexico

${ }^{3}$ Mulliken Center for Theoretical Chemistry, University of Bonn, 53115 Bonn, Germany

${ }^{4}$ Department of Chemistry, Memorial University of Newfoundland, St. John's, NL, A1B 3X7, Canada

*Corresponding author: kjobst@mun.ca 


\section{Table of Contents}

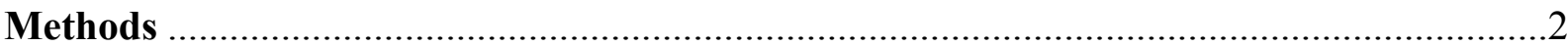

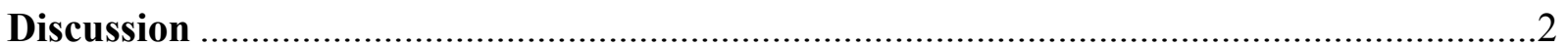

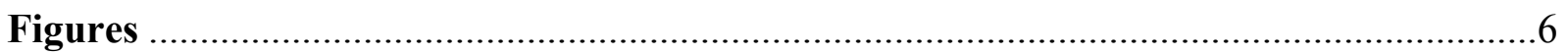

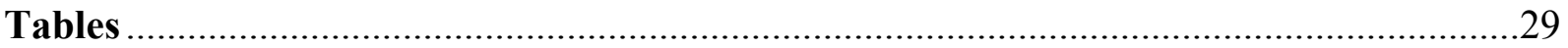

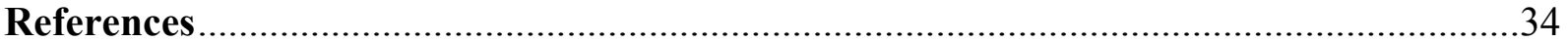

\section{Methods}

EI Spectra of 2-ethylhexyl- 2,3,4,5-tetrabromobenzoate (EH-TBB) and bis(2-ethylhexyl)2,3,4,5-tetrabromophthalate (BEH-TEBP). Standards of EH-TBB and BEH-TEBP were obtained from Wellington Laboratories (Wellington Laboratories Inc., Guelph, ON). Analysis was performed on an Agilent 6890n gas chromatograph coupled to an Agilent 5977 mass spectrometer. The initial temperature was $50^{\circ} \mathrm{C}$, held for 3 minutes; the oven was then ramped at $50{ }^{\circ} \mathrm{C} / \mathrm{min}$ to $250{ }^{\circ} \mathrm{C}$, then at $25^{\circ} \mathrm{C} / \mathrm{min}$ to $320^{\circ} \mathrm{C}$, then held for 15 minutes. Total run time was 24.8 minutes. Mass spectral acquisition was performed in full scan mode. The mass range was from $10 \mathrm{Da}$ to $600 \mathrm{Da}$ for EH-TBB and from $10 \mathrm{Da}$ to $750 \mathrm{Da}$ for BEH-TEBP.

Generation of an alternate input structure for EH-TBB. An alternative input for EH-TBB (Fig. S34) with the necessary conformation for a McLafferty rearrangement was generated by manually modifying the dihedral angle between atoms 3, 4, 5, and 6 in TMoleX (Version 4.4.0, COSMOlogic $\mathrm{GmbH}$ ) from the optimized geometry, such that all numbered atoms lie in the same plane. 


\section{Discussion}

\section{Low match factors among highly brominated compounds (Section 3.1)}

As expected, the spectra of polybrominated diphenyl ethers (PBDEs) with a high degree of bromination, such as decabromodiphenyl ether (BDE-209), generated by QCEIMS (Fig. S-37A) and CFM (Fig. S-3) display intense molecular ions and signals of Br losses. However, the $\mathrm{m} / z$ of the molecular ion and several high-mass fragment ions were calculated to be one mass unit lower than reported in the library. This is because their NIST library spectra are reported using calculated, rather than experimental, nominal masses. ${ }^{1}$ Calculated nominal masses are obtained by summing the masses of all atoms rounded to the nearest integer ${ }^{1}$, whereas the experimental nominal mass is the measured mass of the entire molecule rounded to the nearest integer. The exact masses of both bromine isotopes are lower than their nominal masses (78.918 and 80.916), and thus, the exact mass of the most intense isotopic peak of the $\mathrm{C}_{12} \mathrm{Br}_{10} \mathrm{O}^{\bullet+}$ (BDE-209) molecular ion, $\mathrm{m} / z$ 959.168, is almost a whole mass unit lower than its nominal mass $\mathrm{m} / \mathrm{z} 960$.

\section{Outliers in the overall ranking results and comparisons to collision-induced dissociation (CID) spectra (Section 3.1)}

Similarly to what was discussed regarding match factors (in the main text), the low average rankings of brominated compounds calculated by CFM-EI stem largely from two outliers. These outliers are BDE-209, which was ranked 25th, and 3,3',5-tribromodiphenyl ether (BDE-36), which was ranked 64th (these outliers are visible in Fig. 1D). Aside from tetrabromobisphenol A (TBBPA, ranked 2nd) and one other PBDE (not matched), all other brominated compounds were ranked 1st using CFM-EI, so it is largely the two PBDEs that result in the poor average ranking. The QCEIMS results in the OPFR class are also skewed by a single compound, TCEP, which was ranked 64th (visible in Fig. 1C).

When comparing the spectra predicted by CFM-EI to the CID spectra, there are also a few compounds whose spectra skew the CFM-EI results: only two peaks each (out of twelve) were correctly predicted in the spectra of 1,4,5,6,7,7-hexachloro-N-ethylbicyclo [2,2,1]hept-5-en-2,3dicarboximide and 1,8-dibromo-3,6-dichlorocarbazole, and none in the spectrum of the 
hexachlorobiphenyl, which largely account for the low average results in the chlorinated compounds.

\section{Further discussion on spectra of PBDEs and other halogenated compounds as predicted by QCEIMS (Section 3.2)}

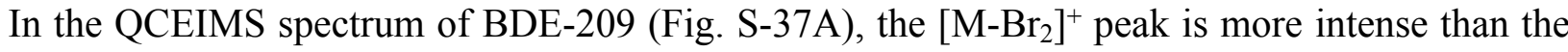
$[\mathrm{M}-\mathrm{Br}]^{+}$peak, whereas in the experimental spectrum (Fig. S37B) the opposite is observed, akin to what is discussed for 2,2',4,4'-tetrabromodiphenyl ether (BDE-47) in the main body of the text. More importantly, the doubly-charged $\left[\mathrm{M}-\mathrm{Br}_{2}\right] / 2$ ion at $m / z 400^{1}$ in the experimental spectrum is not calculated by QCEIMS. As this example shows, doubly charged ions can be important peaks in the mass spectra of halogenated compounds. At present, QCEIMS is not designed to take ions into account that carry more than a single charge ${ }^{2}$.

Halogen atoms are often lost as radicals (as previously discussed), but can also be lost as $\mathrm{HCl}$ or $\mathrm{HBr}$ molecules ${ }^{3}$ if there are hydrogen and halogen atoms adjacent to each other. In the QCEIMS spectrum of BDE-47, several $\mathrm{HBr}$ losses are observed as minor peaks. For example, the $\left[\mathrm{M}-\mathrm{Br}_{3}\right]^{+}$ peak is observed at $m / z 245$ ( $\sim 15 \%$ intensity), and a small peak ( $\sim 3 \%)$ at $\mathrm{m} / \mathrm{z} 244$ corresponds to $\left[\mathrm{M}-\mathrm{HBr}_{3}\right]^{+}$. No $\mathrm{HBr}$ loss peaks were observed at greater than several percent intensity in any QCEIMS spectrum. In experiment, $\mathrm{HCl}$ formation is observed more prominently than $\mathrm{HBr}$ formation ${ }^{3}$ but $\mathrm{HCl}$ loss peaks in the QCEIMS spectra of PCBs were only observed at intensities

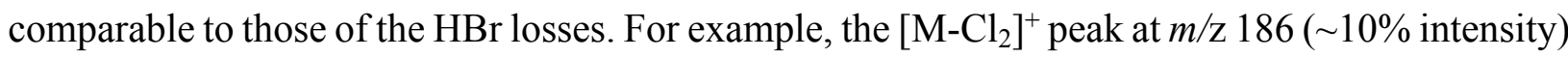
in the spectrum of PCB-28 (Fig. S-18) is accompanied by a peak at $m / z 185$ corresponding to [M$\left.\mathrm{HCl}_{2}\right]^{+}\left(\sim 4 \%\right.$ intensity), and the $\left[\mathrm{M}-\mathrm{H}_{2} \mathrm{Cl}_{2}\right]^{+}$peak is absent. This is a good example for the advantage of using quantum chemistry, as QCEIMS is reasonably accurately computing the chemistry of radical cations, even for minor processes.

\section{COCl loss from 2,3,7,8-tetrachlorodibenzodioxin (TCDD; Section 3.2)}

$[\mathrm{M}-\mathrm{COCl}]^{+}$is an important ion in the spectrum of TCDD (Fig. S-19). ${ }^{4}$ Two mechanisms are possible for its formation: sequential loss of $\mathrm{Cl}^{\cdot}$ followed by $\mathrm{CO}$, or loss of a $\mathrm{COCl}^{\cdot}$ radical. ${ }^{4}$ The $[\mathrm{M}-\mathrm{COCl}]^{+}(\mathrm{m} / z$ 257) ion is correctly calculated by QCEIMS. However, the mechanism between 
the calculations and experiment 41 differ: Eleven trajectories predicted the sequential mechanism reported in the literature, namely loss of $\mathrm{Cl}^{\bullet}$ followed by $\mathrm{CO}$, but ten trajectories predicted $\mathrm{CO}$ loss followed by $\mathrm{Cl}^{\bullet}$ loss, which is contrary to experiment. ${ }^{4}$ Formation of $[\mathrm{M}-\mathrm{COCl}]^{+}$via a concerted

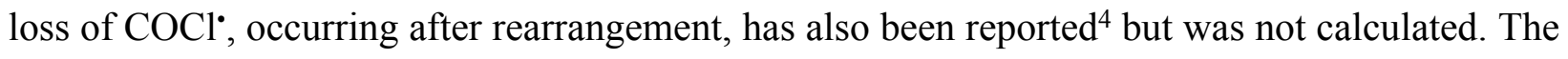
only two trajectories involving the formation of a $\mathrm{COCl}$ moiety formed $\mathrm{COCl}^{+}$, not $\mathrm{COCl}^{\circ}$, and yielded $\mathrm{COCl}$ only as a result of extensive fragmentation of the molecule. The intensity of the [M$\mathrm{COCl}]^{+}$ion is lower than in the experimental spectrum (Fig. S19), in part because the rearrangement reaction is not correctly calculated.

\section{Further discussion on the dissociation chemistry of organophosphorus flame retardants (Section 3.3)}

Similarly to the example of tricresyl phosphate (TCP) in the main body of the text, the fragment of highest mass in the QCEIMS spectrum of tris(tert-butylphenyl) phosphate (TIBPP; Fig. S-30A) is $\left[\mathrm{M}_{-} \mathrm{C}_{10} \mathrm{H}_{13} \mathrm{O}\right]^{+}$at $m / z 345$, and the base peak is $m / z 149$, which corresponds to $\left[\mathrm{C}_{10} \mathrm{H}_{13} \mathrm{O}\right]^{+}$. This result cannot be brought to accordance with the experimental CID spectrum (Fig. S-30D), in which the molecular ion has a larger intensity and an $\left[\mathrm{M}-\mathrm{CH}_{3}\right]^{+}$ion is displayed at $m / z 479$. Unlike QCEIMS, CFM-EI correctly predicted the main peaks in the CID spectrum of TIBPP: the intense methyl loss peak and the small butyl loss peak ( $\mathrm{m} / \mathrm{z} 479$ and $\mathrm{m} / \mathrm{z} 439$, respectively) are present in the CFM-EI spectrum of TIBPP (Fig. S-30B).

As stated in the main body of the text, four OPFR compounds also produced $[\mathrm{M}+\mathrm{H}]^{+}$ions in addition to $\mathrm{M}^{\bullet+}$ ions in APCI, and tris(1,3-dichloro-2-propyl) phosphate (TDCPP) produced only $[\mathrm{M}+\mathrm{H}]^{+}$ions. These compounds are indicated in Table $1 .[\mathrm{M}+\mathrm{H}]^{+}$ions have different potential energy surfaces (PESs) than their radical counterparts, meaning that a direct comparison to predicted EI spectra is not possible. A method designed to predict CID spectra of $[\mathrm{M}+\mathrm{H}]^{+}$ions, CFM-ESI, was applied to the five compounds that formed $[\mathrm{M}+\mathrm{H}]^{+}$ions. In general, CFM-ESI and CFM-EI predicted similar fragmentation. While CFM-EI generally predicted more fragments than CFM-ESI, in agreement with experiment, most peaks predicted by CFM-ESI were also predicted by CFM-EI. One exception was TIBPP, where the highest-mass predicted fragment using CFMEI was $\left[\mathrm{M}-\mathrm{CH}_{3}\right]^{+}$, whereas using CFM-ESI it was $\left[\mathrm{M}-\mathrm{H}_{2} \mathrm{O}\right]^{+}$. For TCP, CFM-ESI also assigned

charges incorrectly, predicting a base peak of $m / z 91\left(\left[\mathrm{C}_{7} \mathrm{H}_{7}\right]^{+}\right)$. None of the OPFRs in this study 
were present in the Metlin metabolomics database which was used to train CFM-ESI, which may account for some of the variability observed in the results CFM. 
Figures
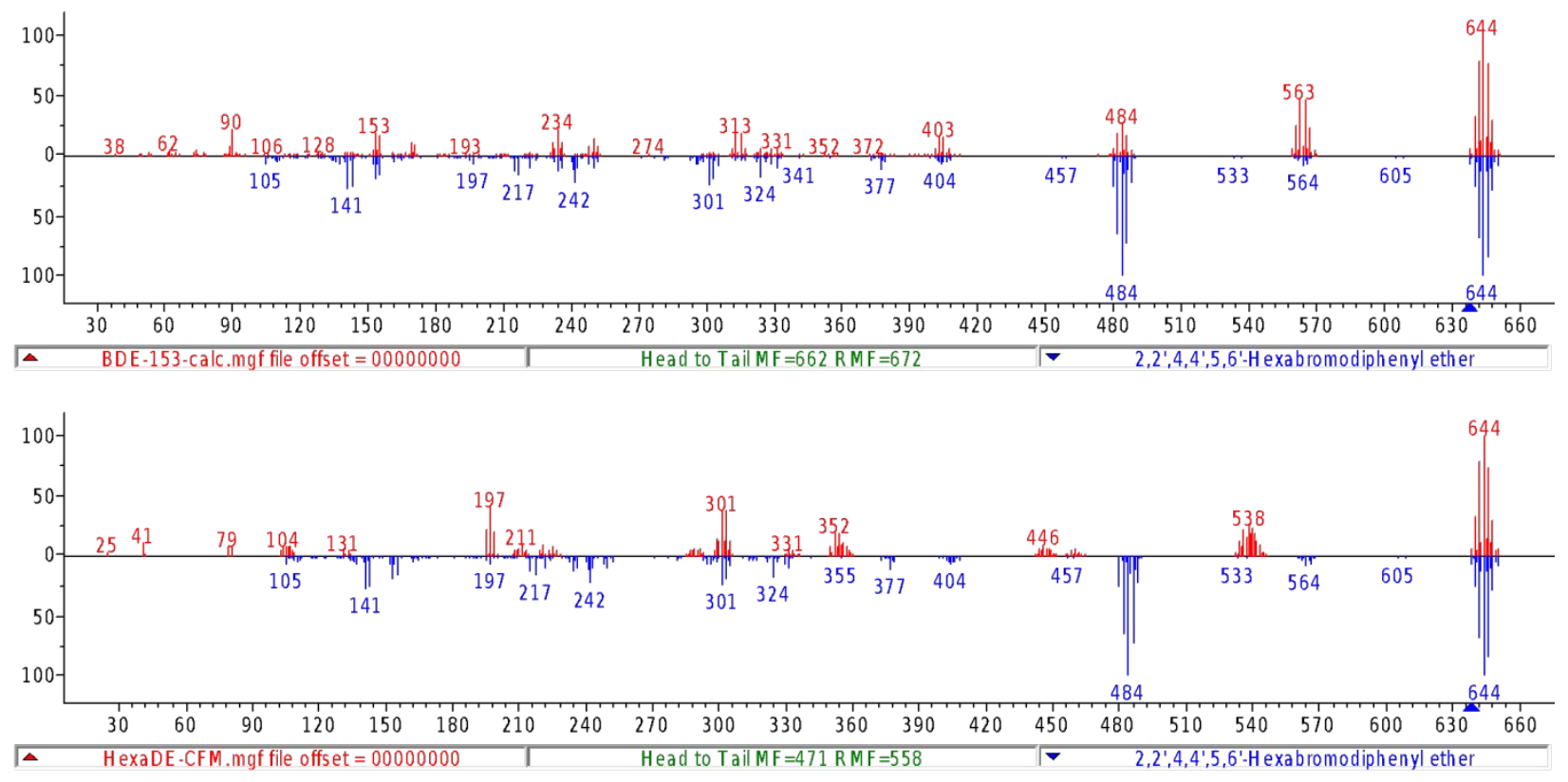

Figure S-1. QCEIMS spectrum (top, red) and CFM-EI spectrum (bottom, red) compared to NIST Database EI spectrum (blue) of 2,2',4,4',5,5'-hexabromodiphenyl ether (BDE-153).
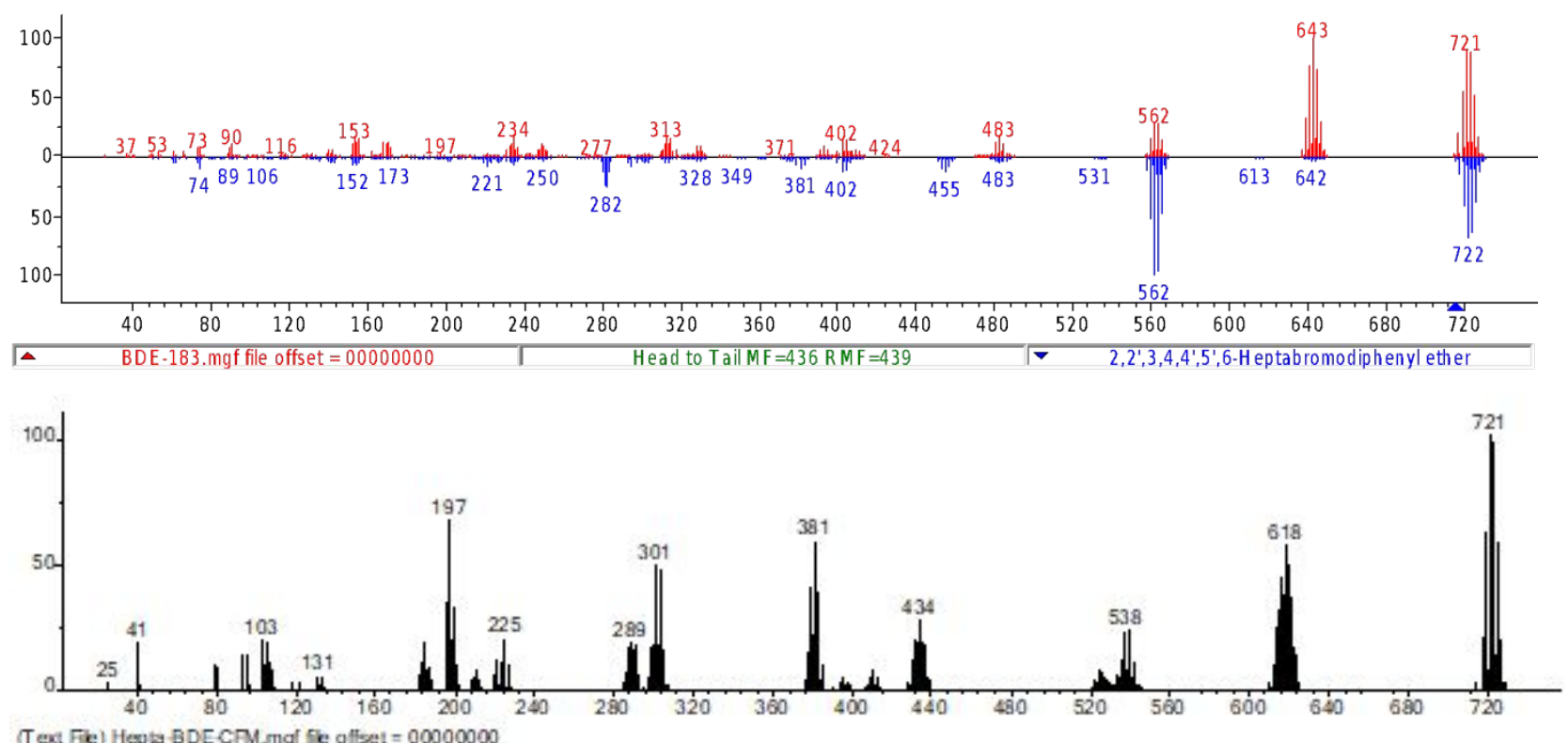

Figure S-2. Top: QCEIMS spectrum (red) compared to NIST Database EI spectrum (blue) of 2,2',3,4,4',5',6heptabromodiphenyl ether (BDE-183). Bottom: CFM-EI spectrum of BDE-183. 


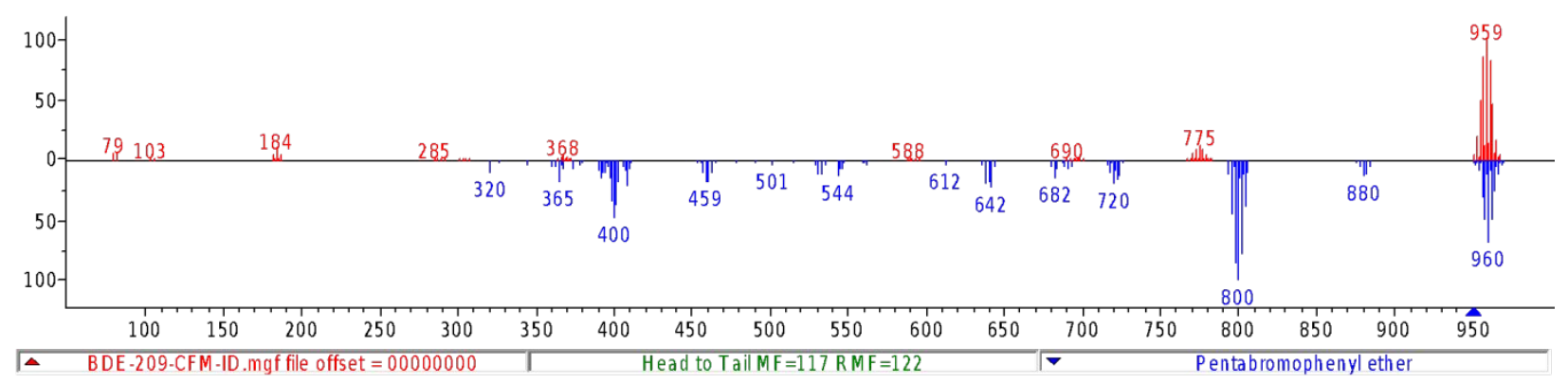

Figure S-3. CFM-EI spectrum (red) compared to NIST Database EI spectrum (blue) of decabromodiphenyl ether (BDE-209).
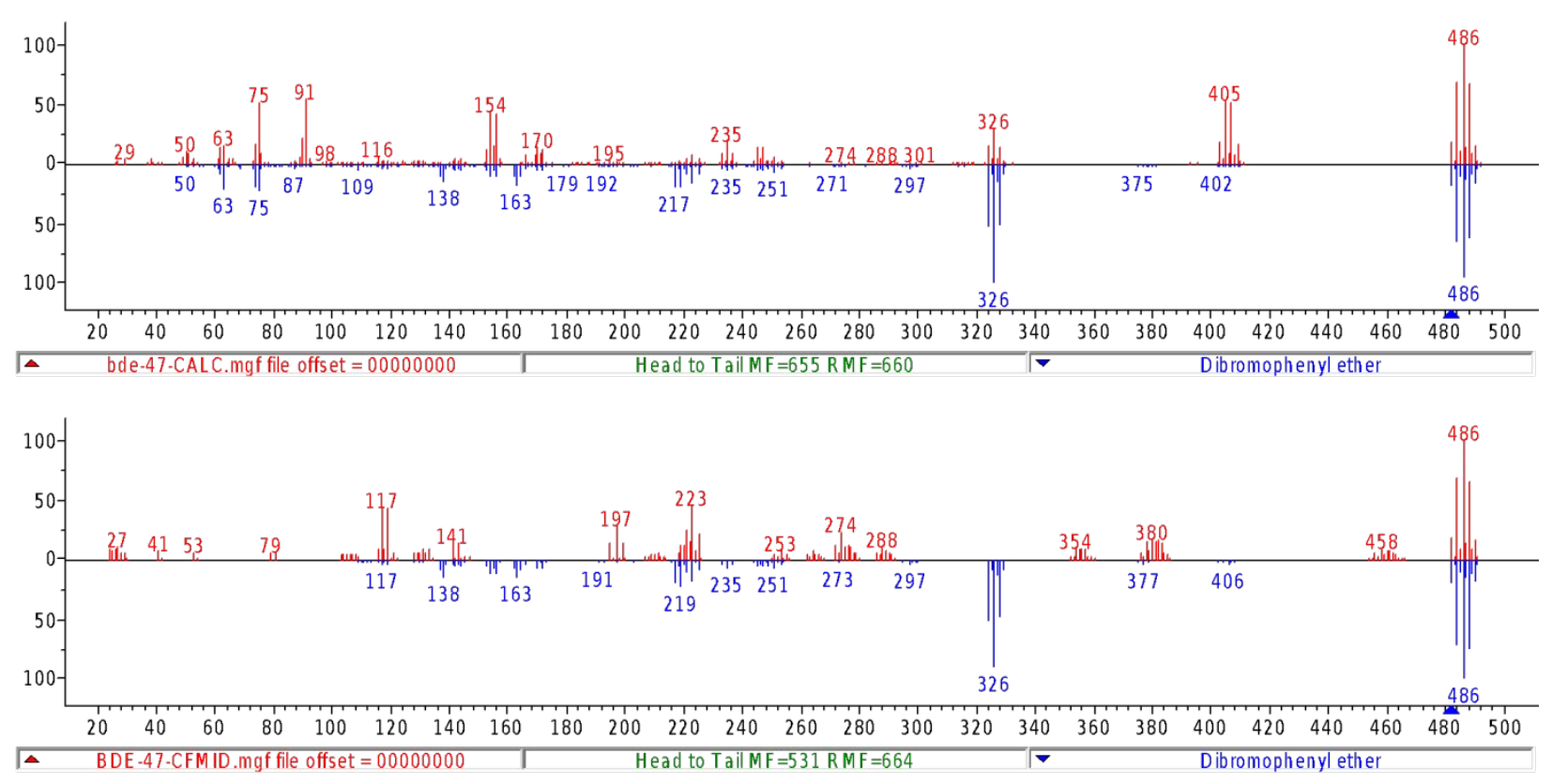

Figure S-4. QCEIMS spectrum (top, red) and CFM-EI spectrum (bottom, red) compared to NIST Database EI spectrum (blue) of 2,2',4,4'-tetrabromodiphenyl ether (BDE-47). 

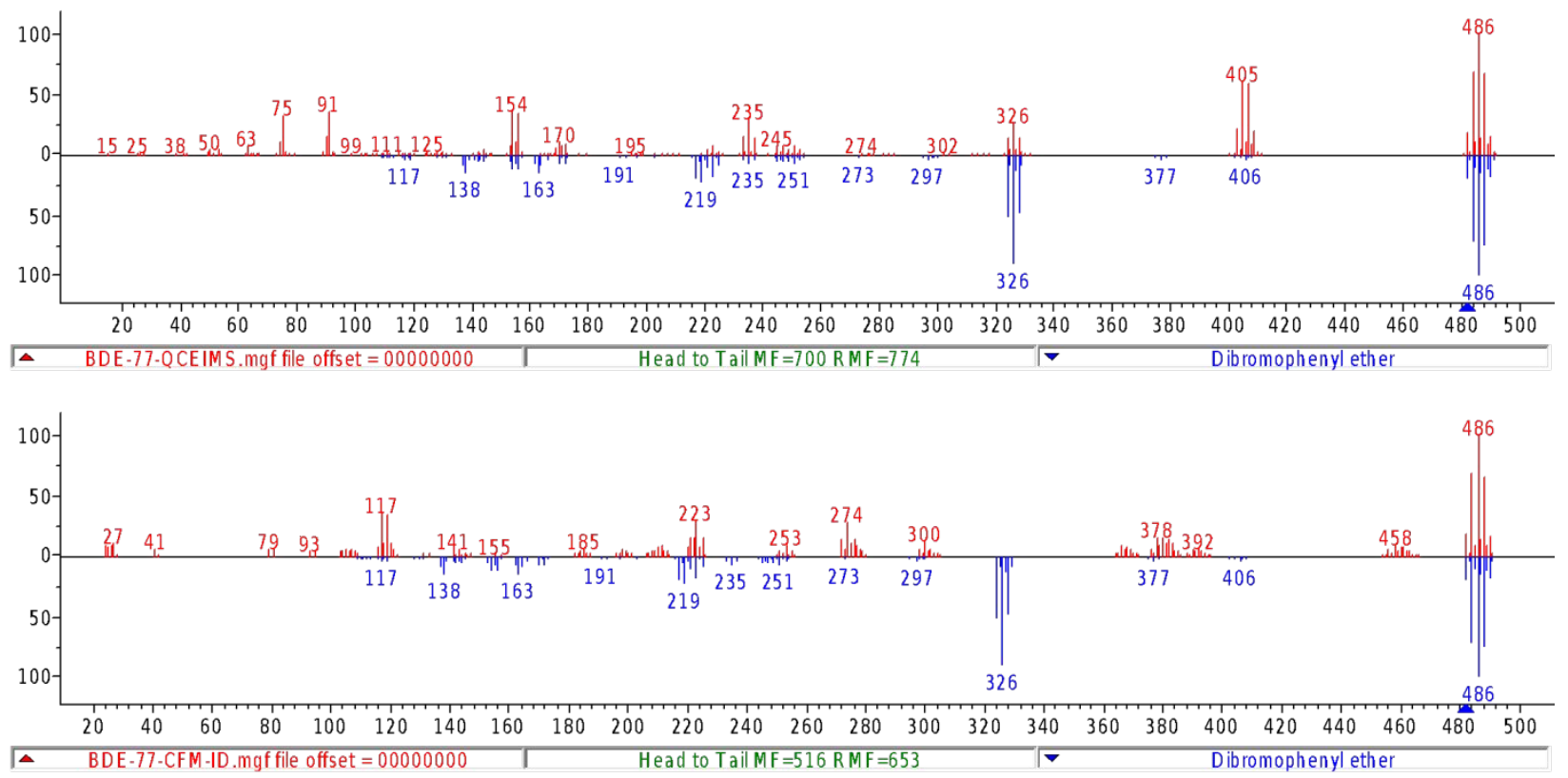

Figure S-5. QCEIMS spectrum (top, red) and CFM-EI spectrum (bottom, red) compared to NIST Database EI spectrum (blue) of 3,3',4,4'-tetrabromodiphenyl ether (BDE-77).
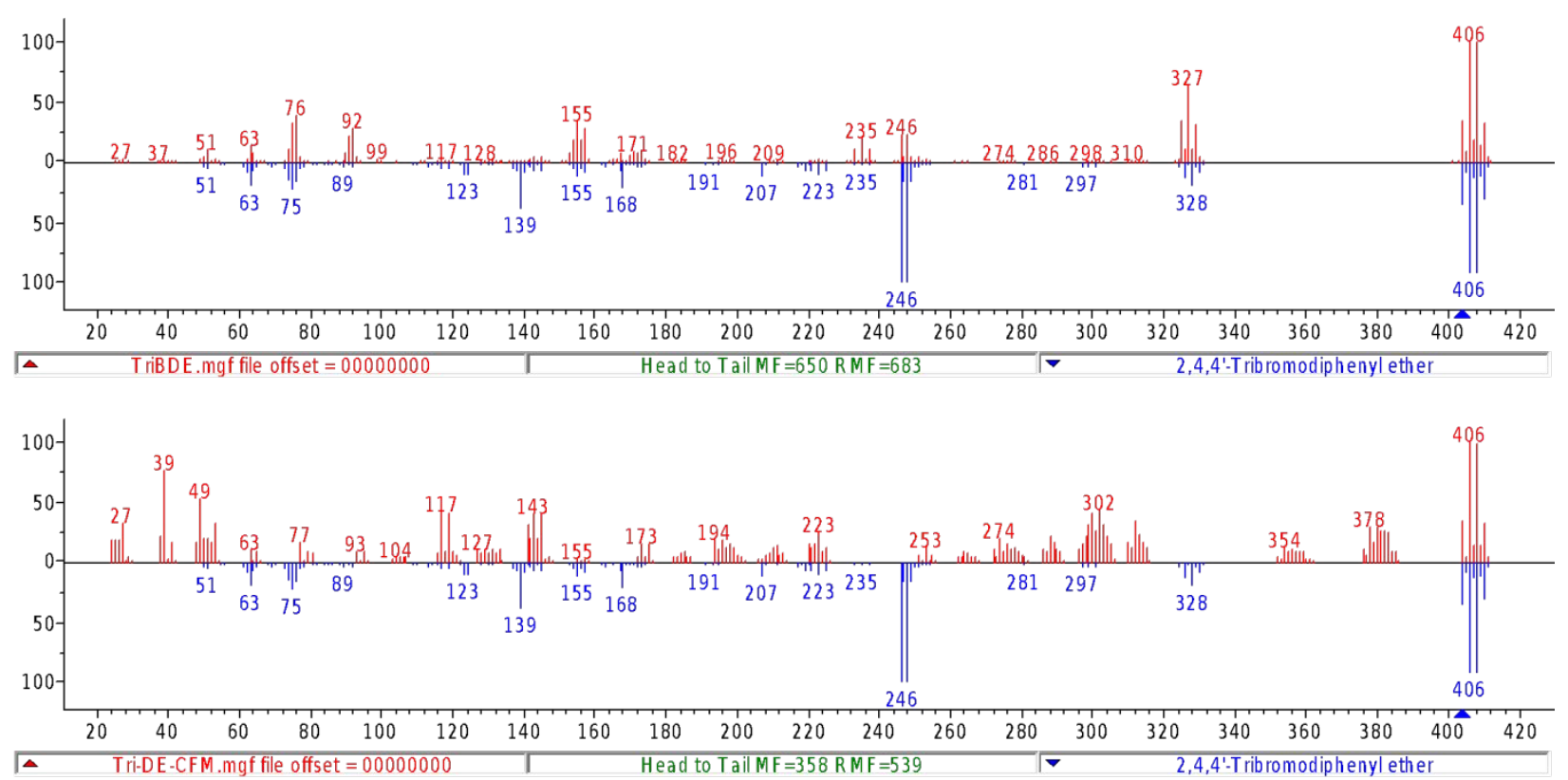

Figure S-6. QCEIMS spectrum (top, red) and CFM-EI spectrum (bottom, red) compared to NIST Database EI spectrum (blue) of 3,3',5-tribromodiphenyl ether (BDE-36). 


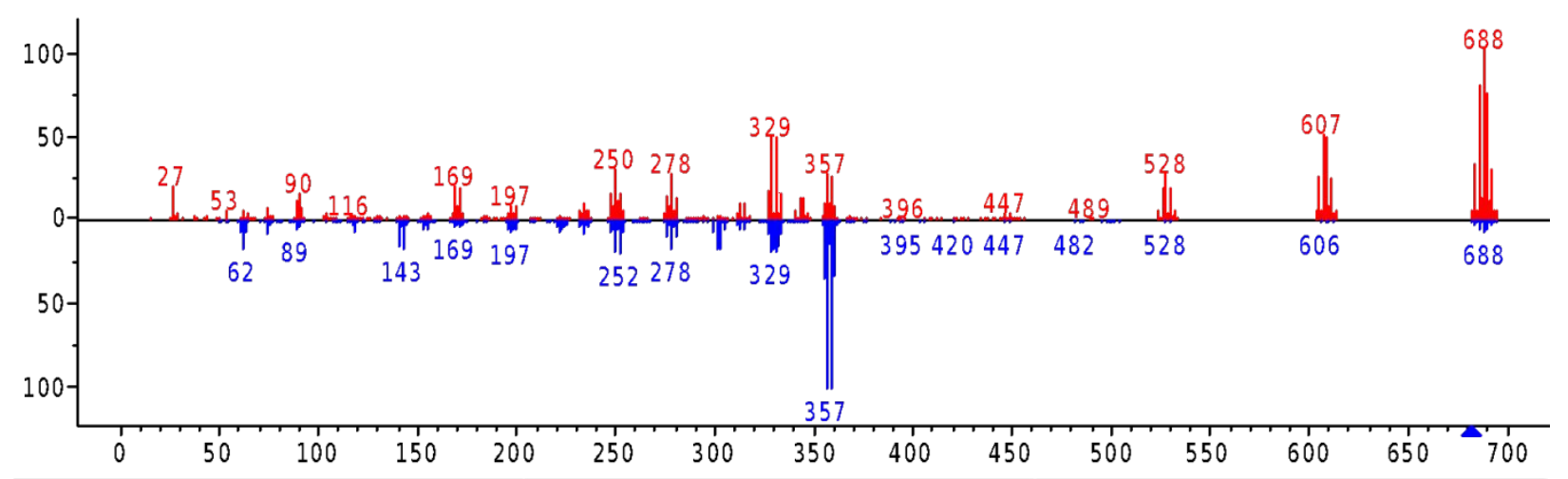

$\triangle$ BTBPE-calc. mgf file offset $=00000000 \quad$ Head to Tail MF $=472$ RMF $=564 \quad \nabla$ Benzene, 1,1'-[1,2-ethanediylbis(0xy) $]$ bis $[2$

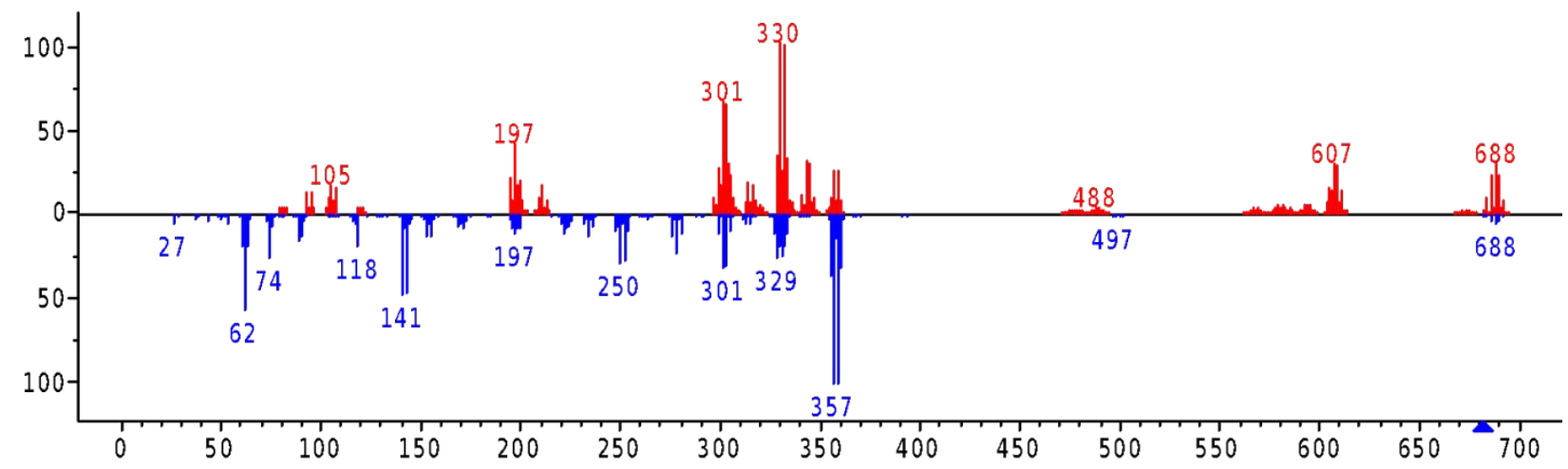

$\triangle B$ B BPE-CFM-2.mgf file offset $=00000000 \quad$ Head to Tail MF $=239$ RMF $=340 \quad \nabla$ Benzene, 1,1'-[1,2-ethanediylbis(oxy)]bis[2

Figure S-7. QCEIMS spectrum (top, red) and CFM-EI spectrum (bottom, red) compared to NIST Database EI spectrum (blue) of 1,2-bis(2,4,6-tribromo-phenoxy) ethane (BTBPE).
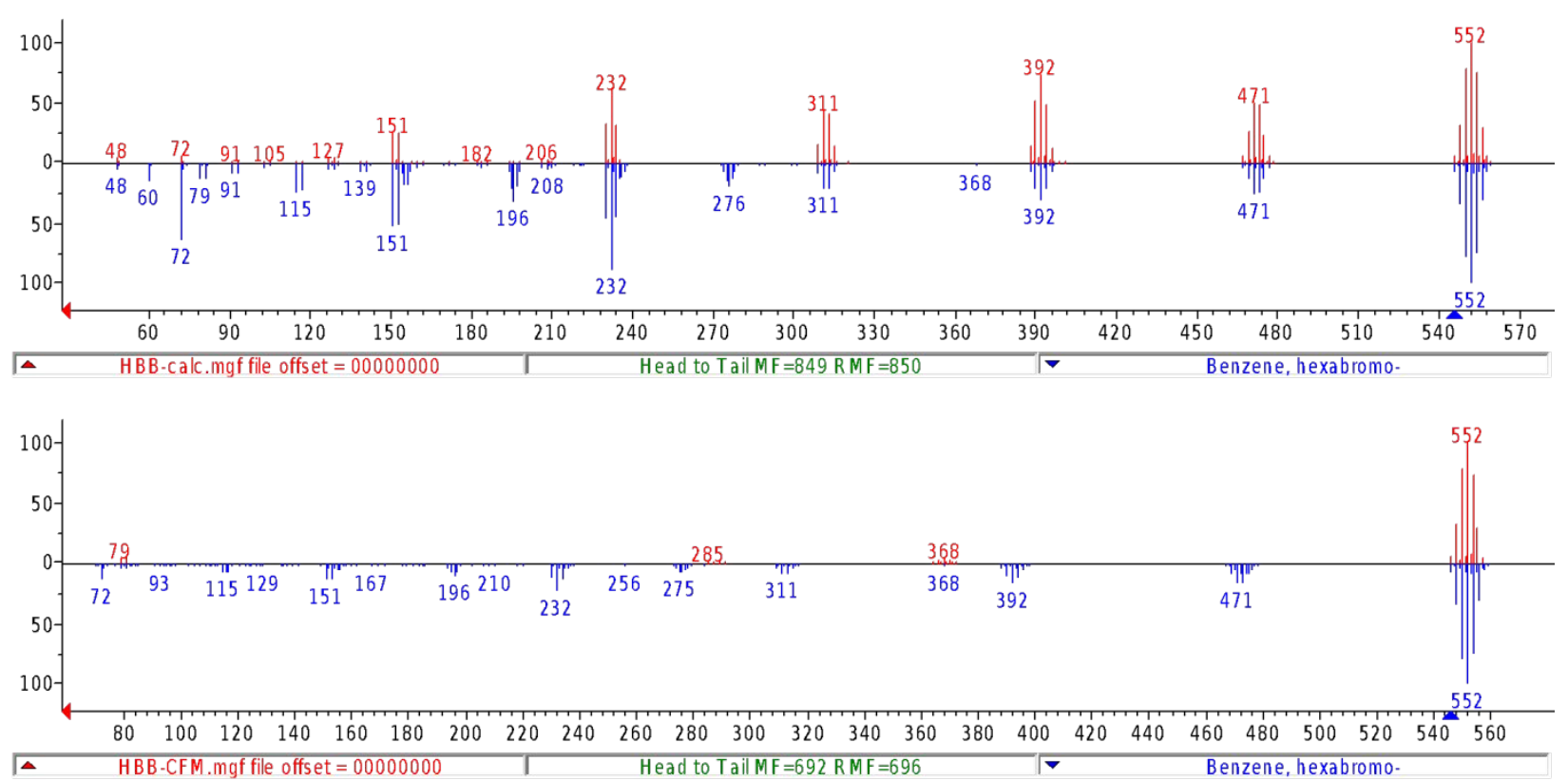

Figure S-8. QCEIMS spectrum (top, red) and CFM-EI spectrum (bottom, red) compared to NIST Database EI spectrum (blue) of hexabromobenzene (HBB). 


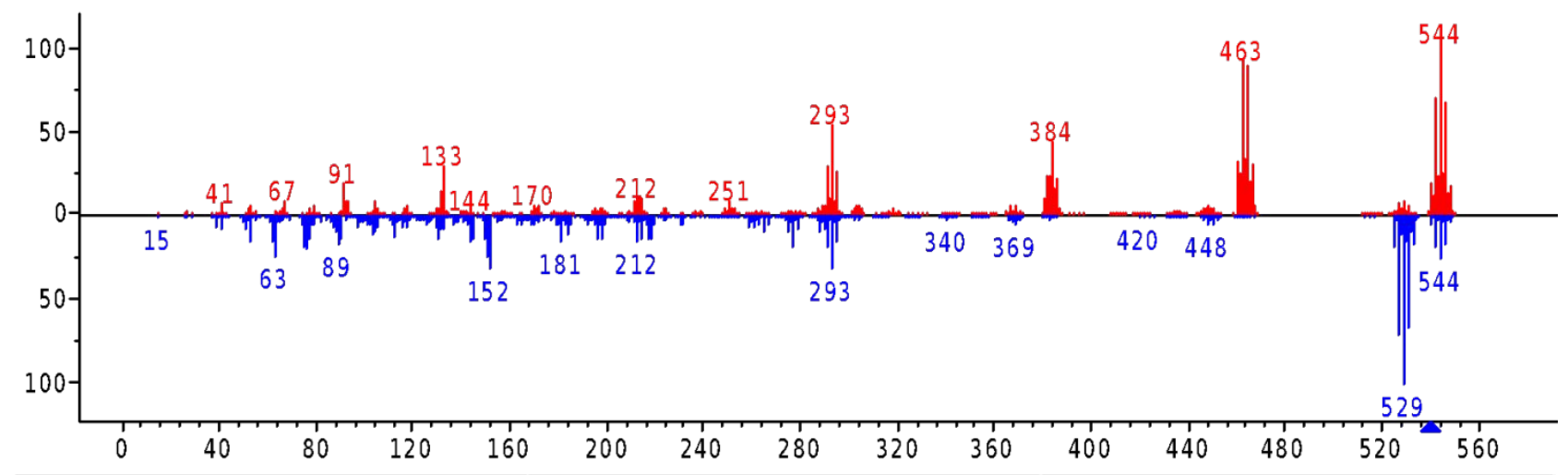

$\triangle$ TBBPA-calc. $m g f$ file offset $=00000000 \quad$ Head to Tail MF $=349$ RMF $=368 \quad \nabla$ Phenol, 4,4'-(1-methylethylidene $)$ bis [2,6-di

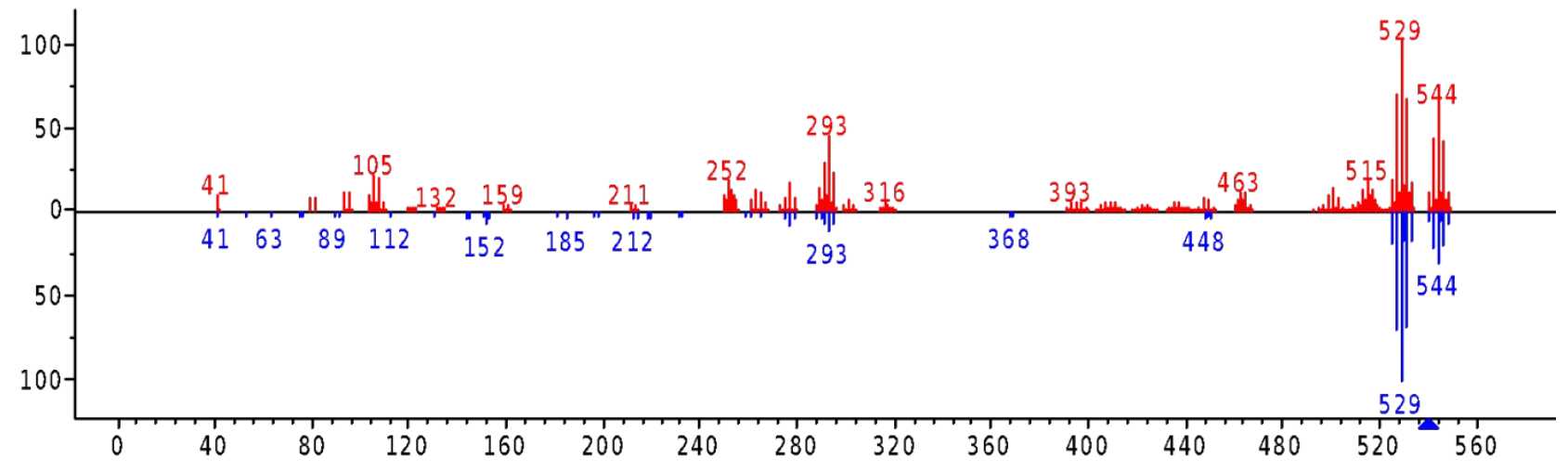

$\triangle$ TBBPA-CFM-2.mgf file offset $=00000000 \quad$ Head to Tail MF $=405$ R MF $=806 \quad \nabla$ Phenol, 4,4'-(1-methylethylidene) bis $[2,6$-di Figure S-9. QCEIMS spectrum (top, red) and CFM-EI spectrum (bottom, red) compared to NIST Database EI spectrum (blue) of tetrabromobisphenol A (TBBPA).

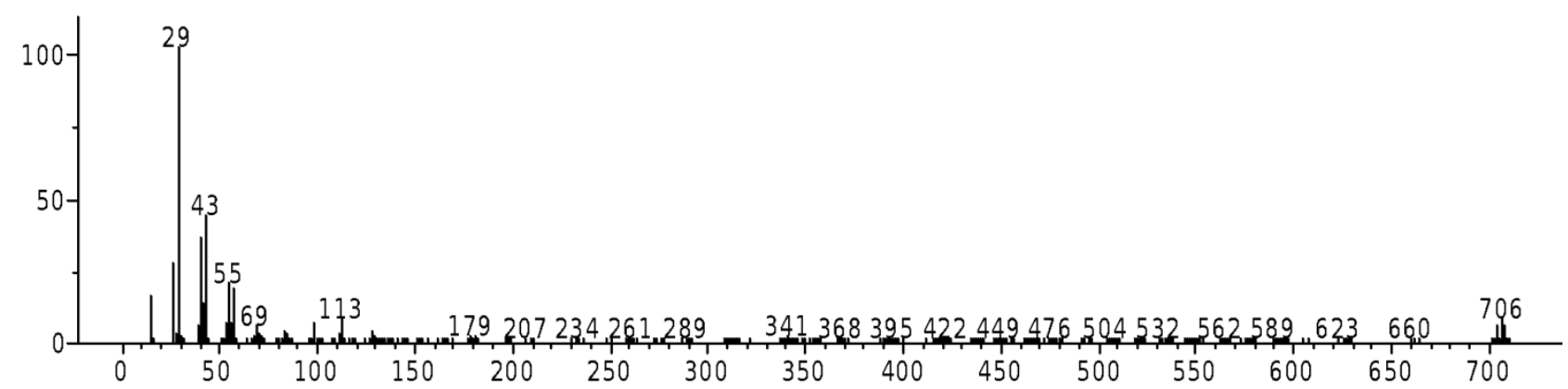

(History) TBPH -calc .mgf file offset $=00000000$ 


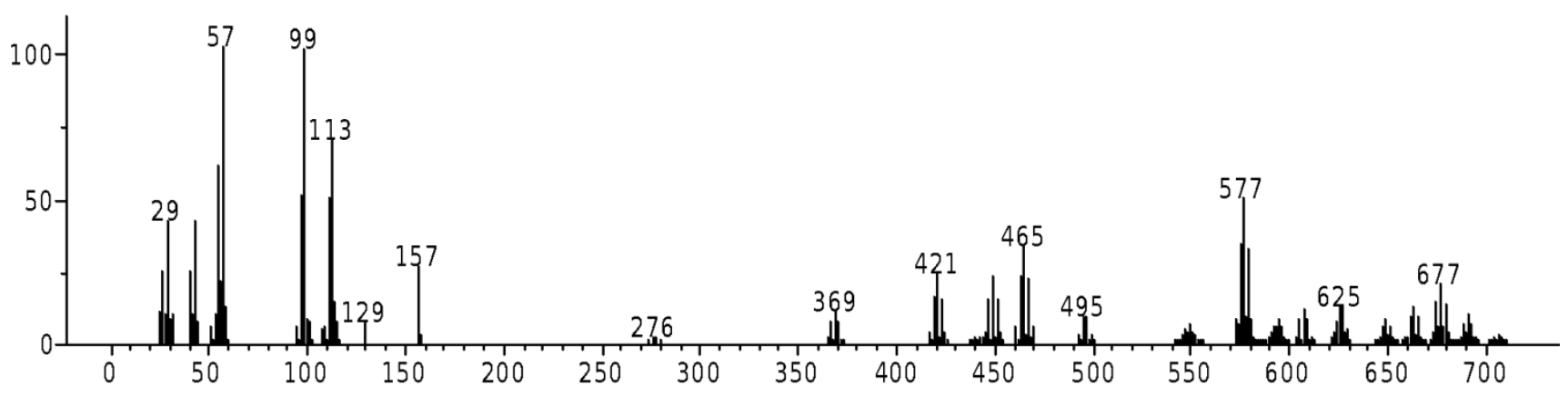

(History) TBPH -CFM.mgf file offset $=00000000$

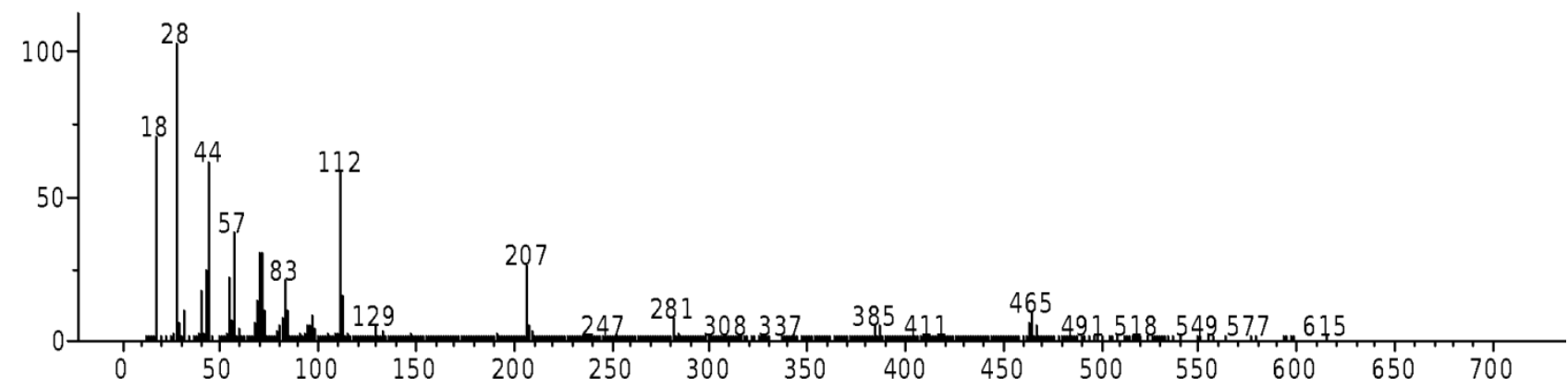

(History) TBPH -El.mgf file offset $=00000000$

Figure S-10. QCEIMS spectrum (top), CFM-EI spectrum (centre), and experimental EI spectrum (bottom) of BEHTEBP.
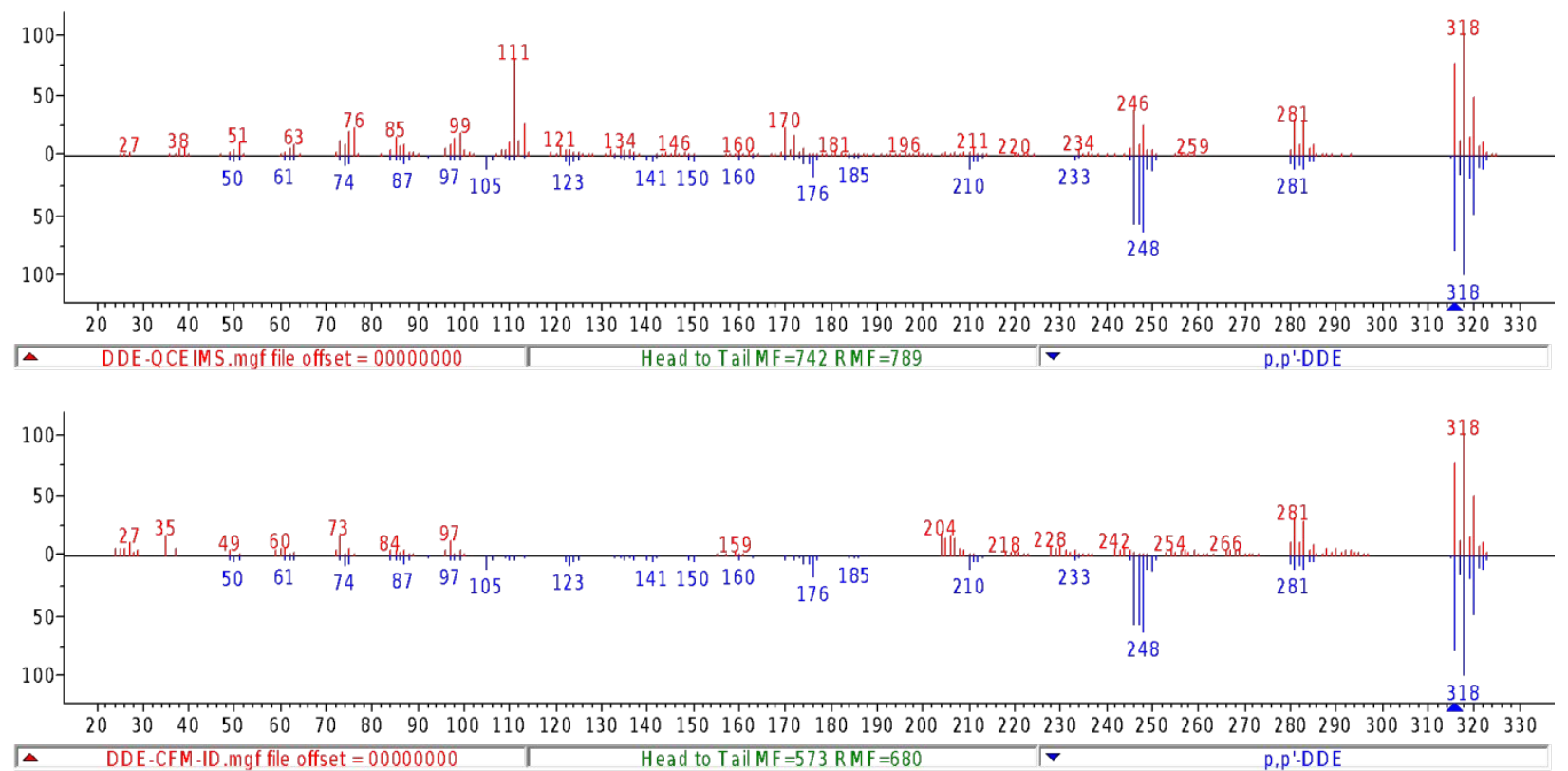

Figure S-11. QCEIMS spectrum (top, red) and CFM-EI spectrum (bottom, red) compared to NIST Database EI spectrum (blue) of dichlorodiphenyldichloroethylene (DDE). 

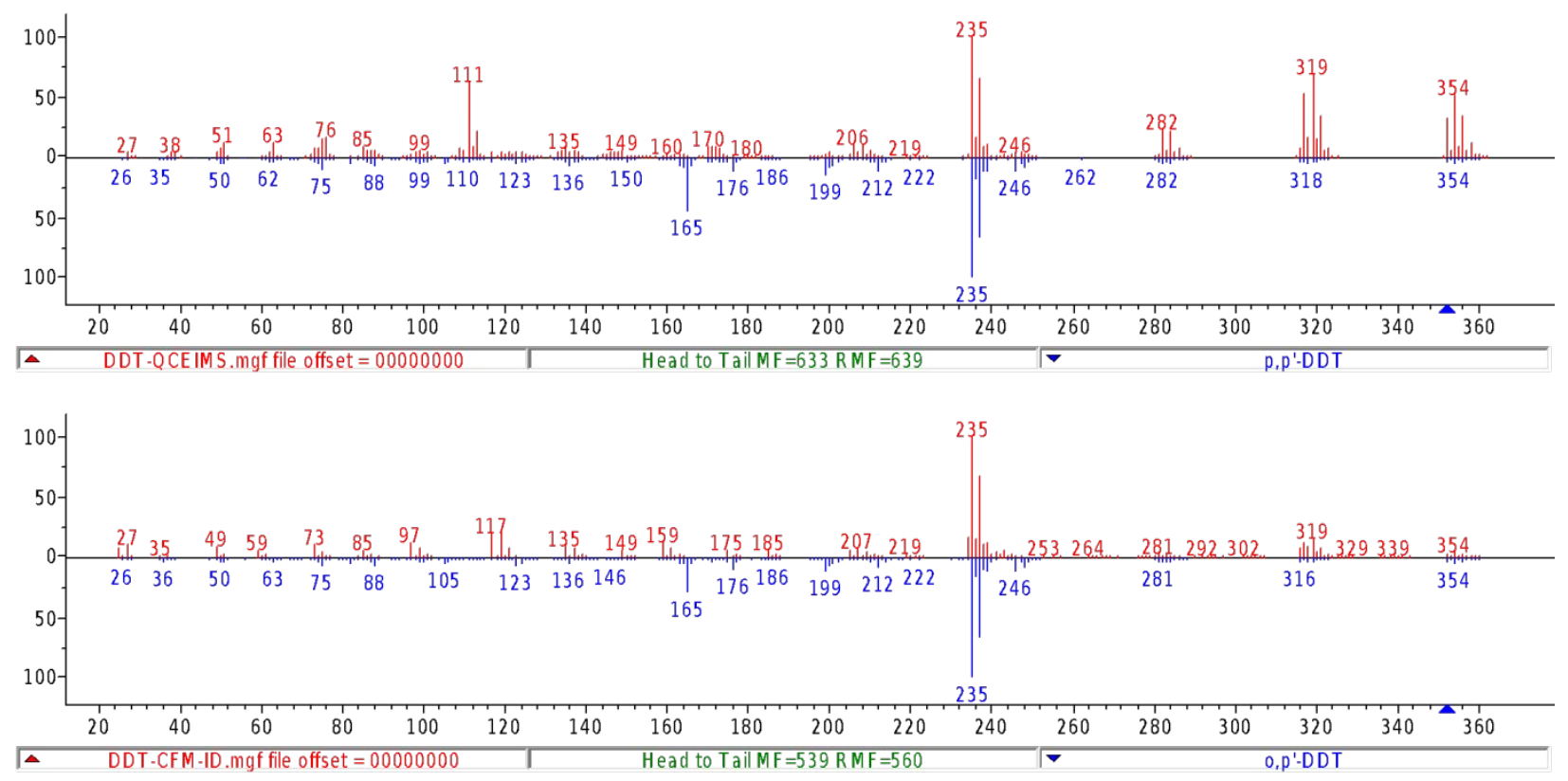

Figure S-12. QCEIMS spectrum (top, red) and CFM-EI spectrum (bottom, red) compared to NIST Database EI spectrum (blue) of dichlorodiphenyltrichloroethane (DDT).
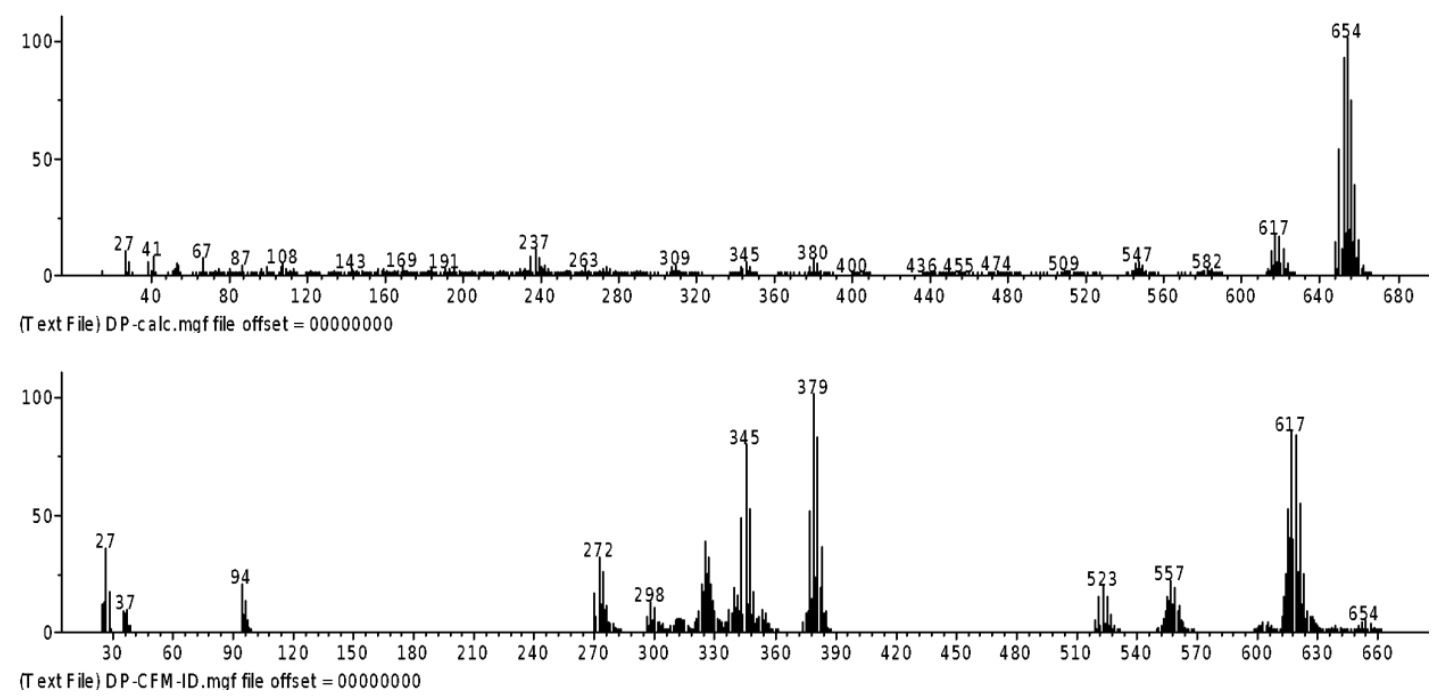

Figure S-13. QCEIMS spectrum (top) and CFM-EI spectrum (bottom) of Dechlorane Plus (DP). 

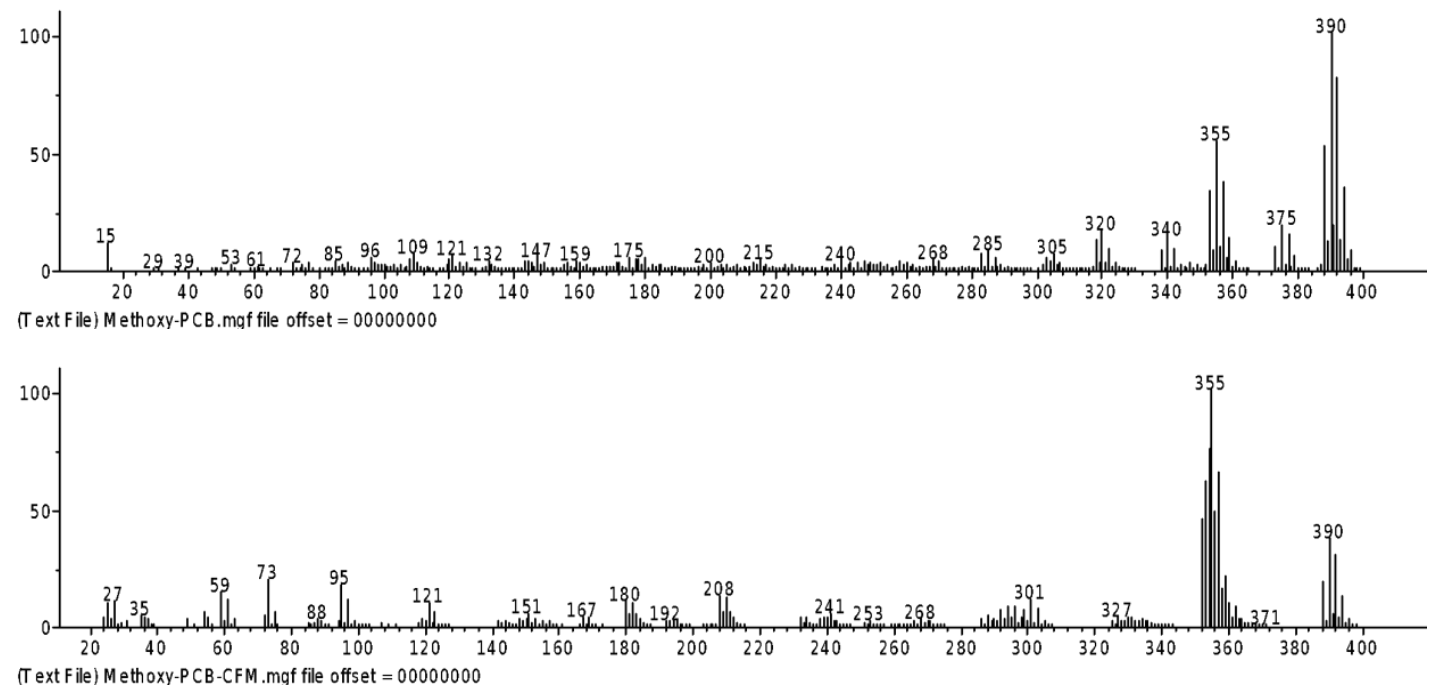

Figure S-14. QCEIMS spectrum (top) and CFM-EI spectrum (bottom) of 4-OH-2',3,3',4',5,5'-hexachlorobiphenyl.
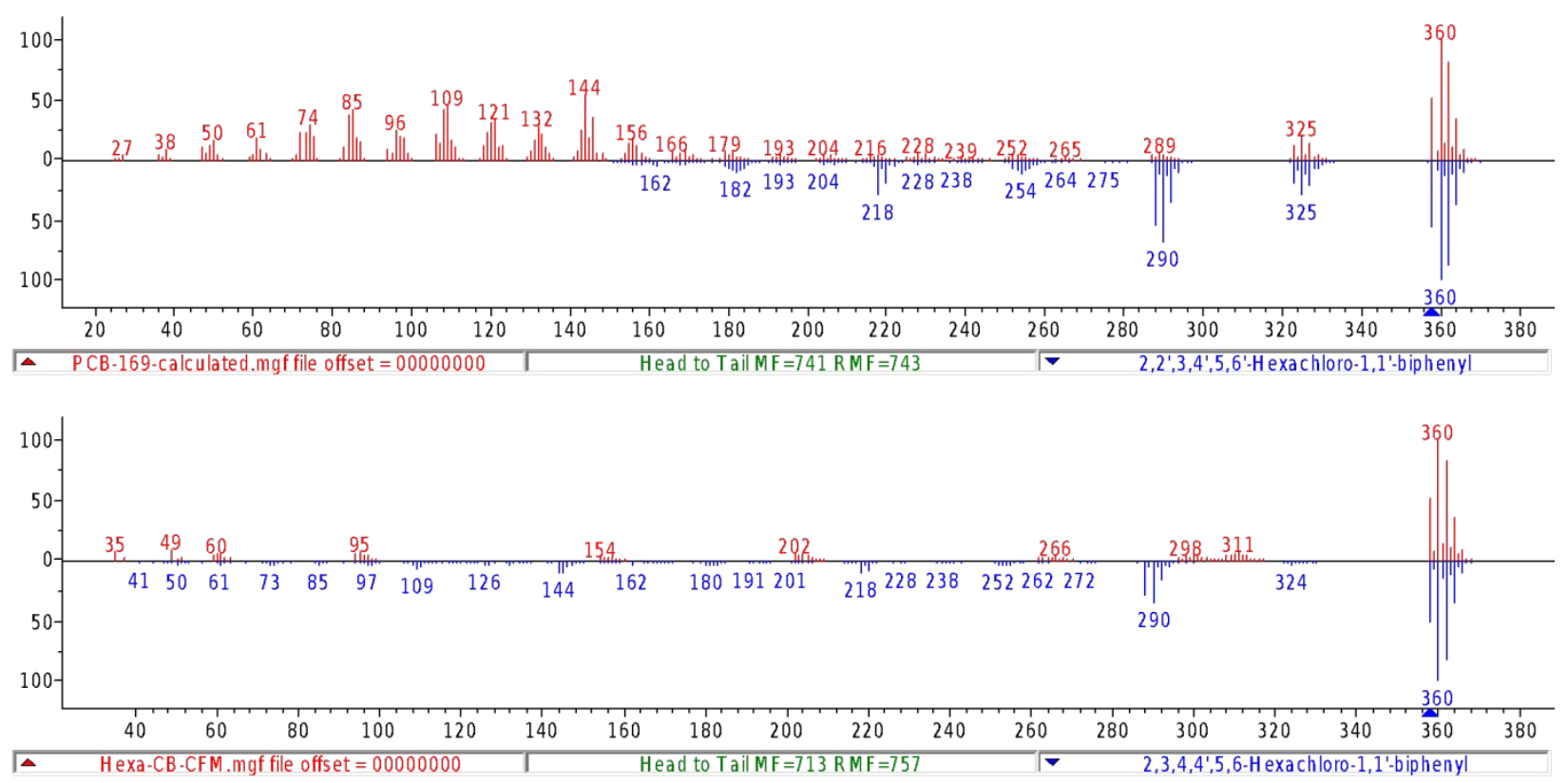

Figure S-15. QCEIMS spectrum (top, red) and CFM-EI spectrum (bottom, red) compared to NIST Database EI spectrum (blue) of 3,3',4,4',5,5'-hexachlorobiphenyl (PCB-169). 

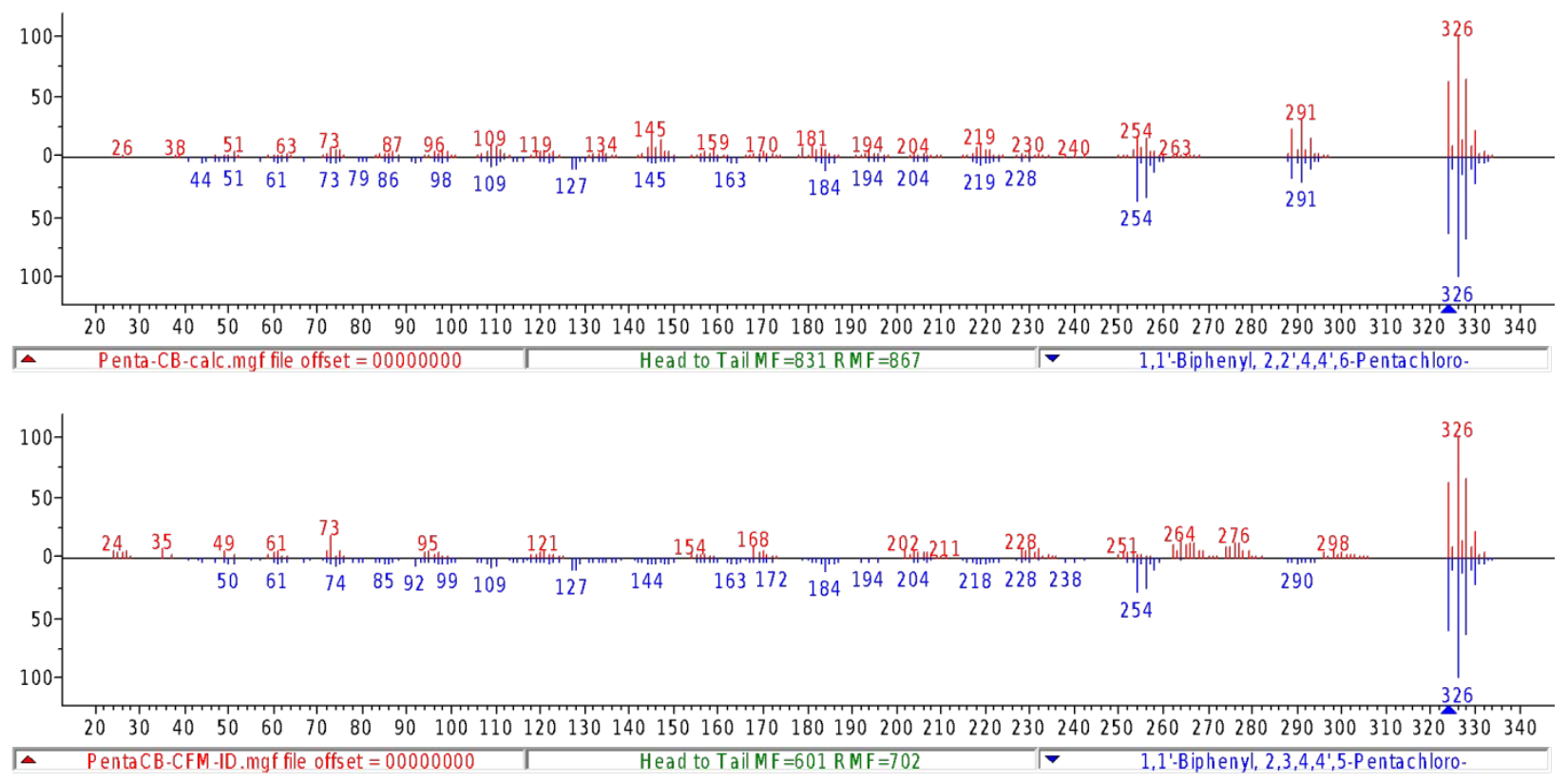

Figure S-16. QCEIMS spectrum (top, red) and CFM-EI spectrum (bottom, red) compared to NIST Database EI spectrum (blue) of 2,4,4',5,5'-pentachlorobiphenyl (PCB-118).
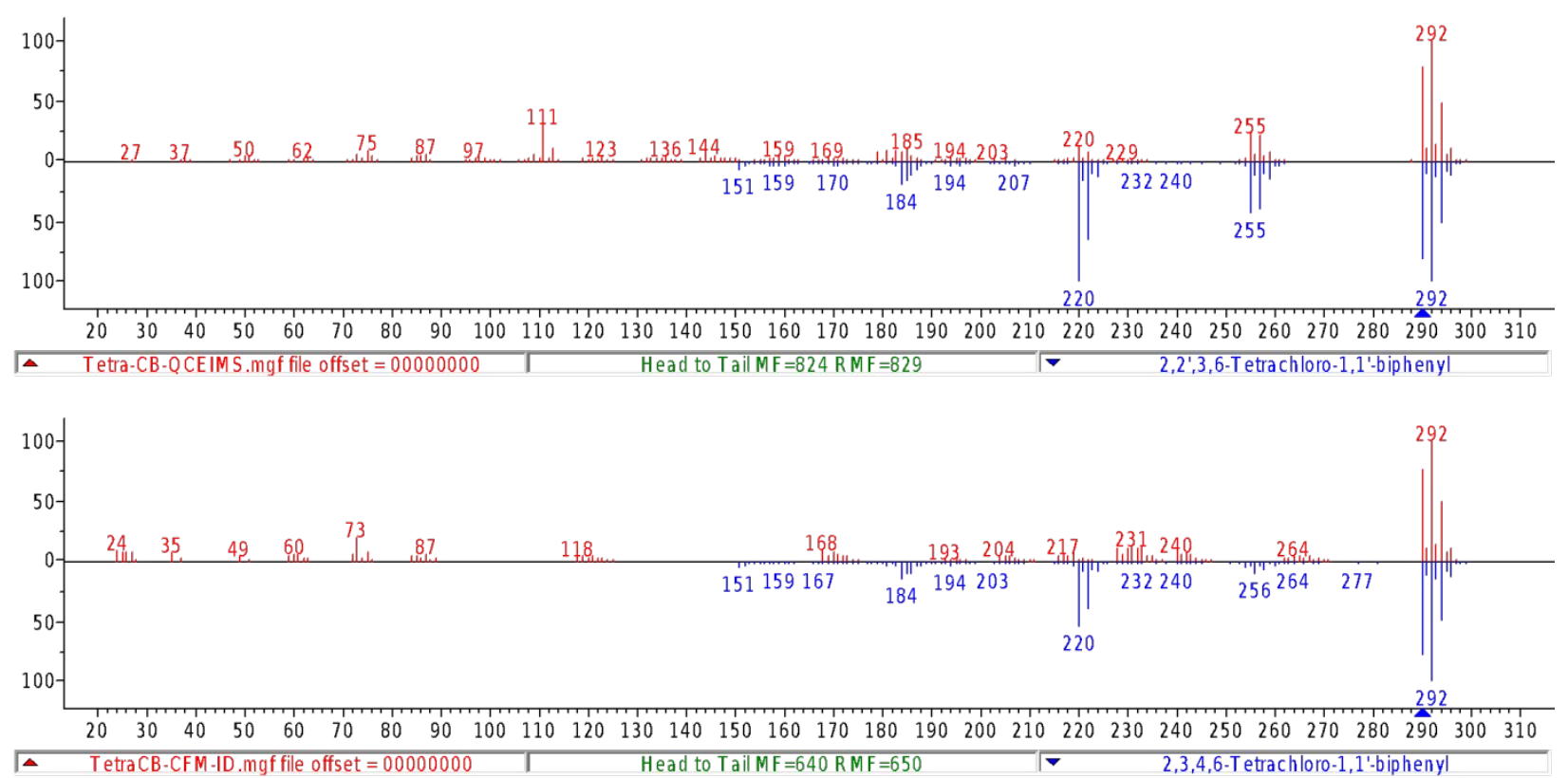

Figure S-17. QCEIMS spectrum (top, red) and CFM-EI spectrum (bottom, red) compared to NIST Database EI spectrum (blue) of 2,4,4',5-tetrachlorobiphenyl (PCB-74). 

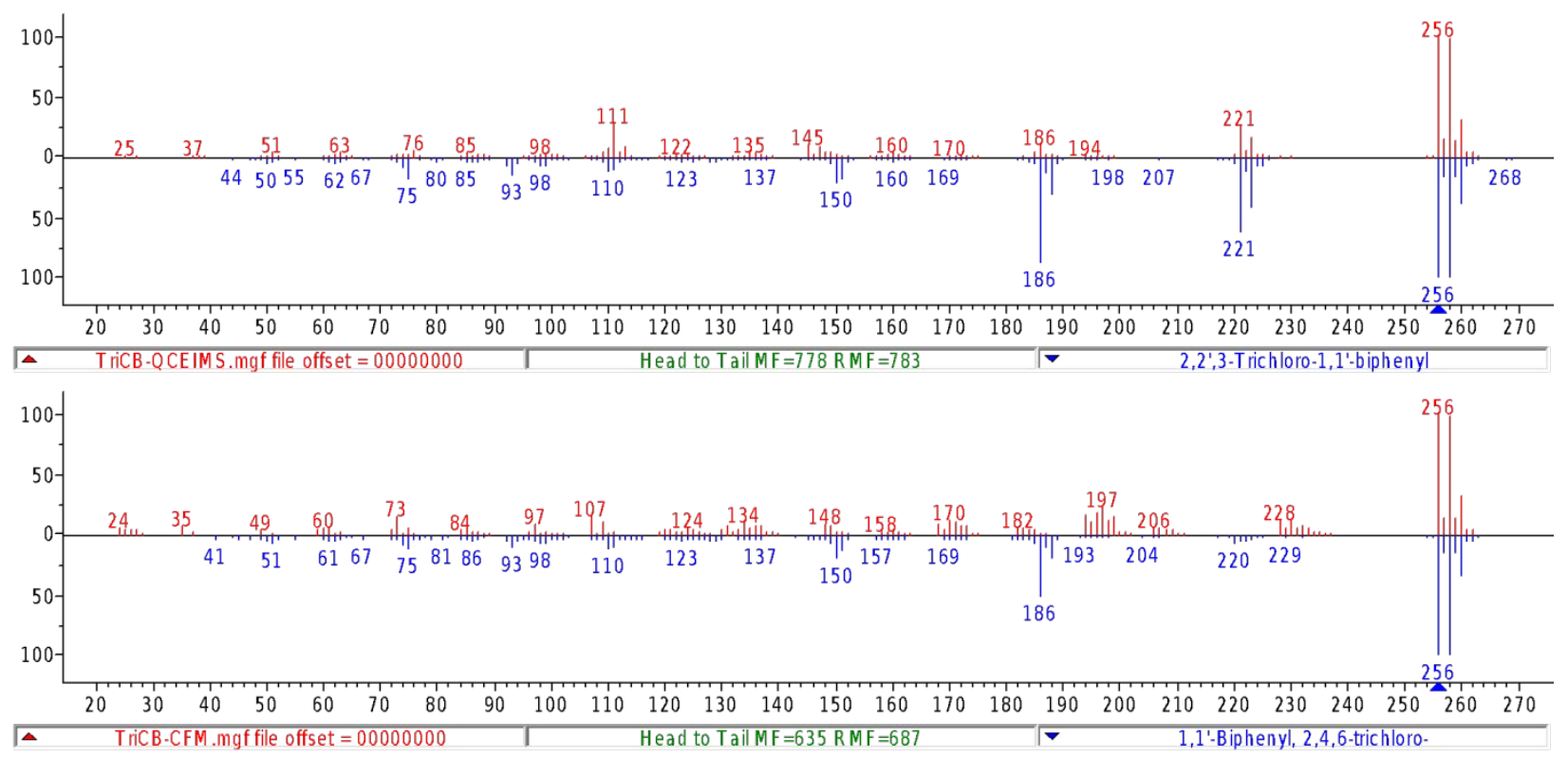

Figure S-18. QCEIMS spectrum (top, red) and CFM-EI spectrum (bottom, red) compared to NIST Database EI spectrum (blue) of 2,4,4'-trichlorobiphenyl (PCB-28).

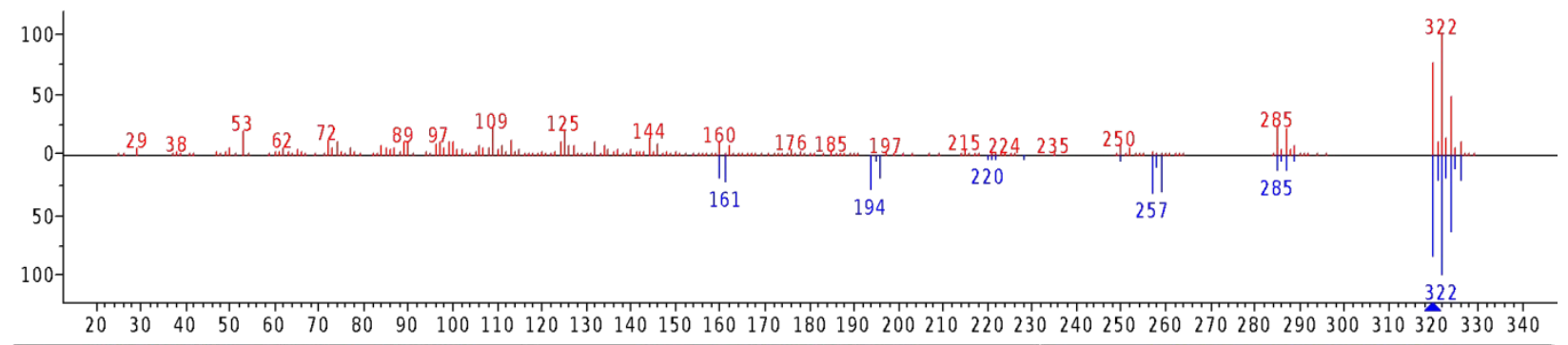

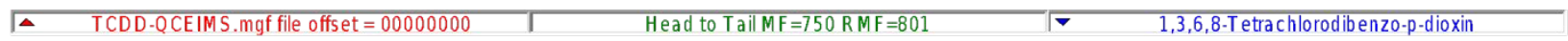

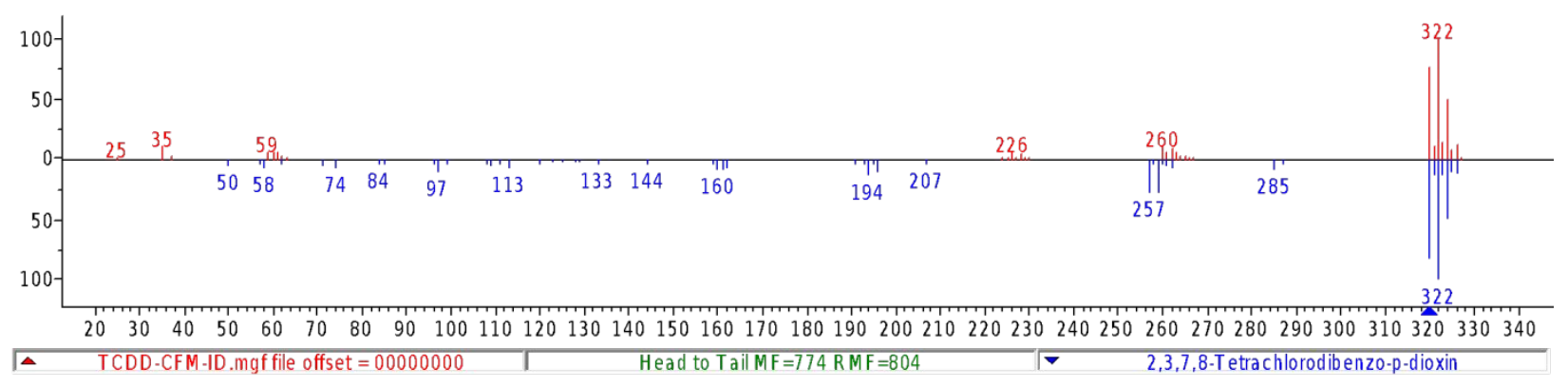




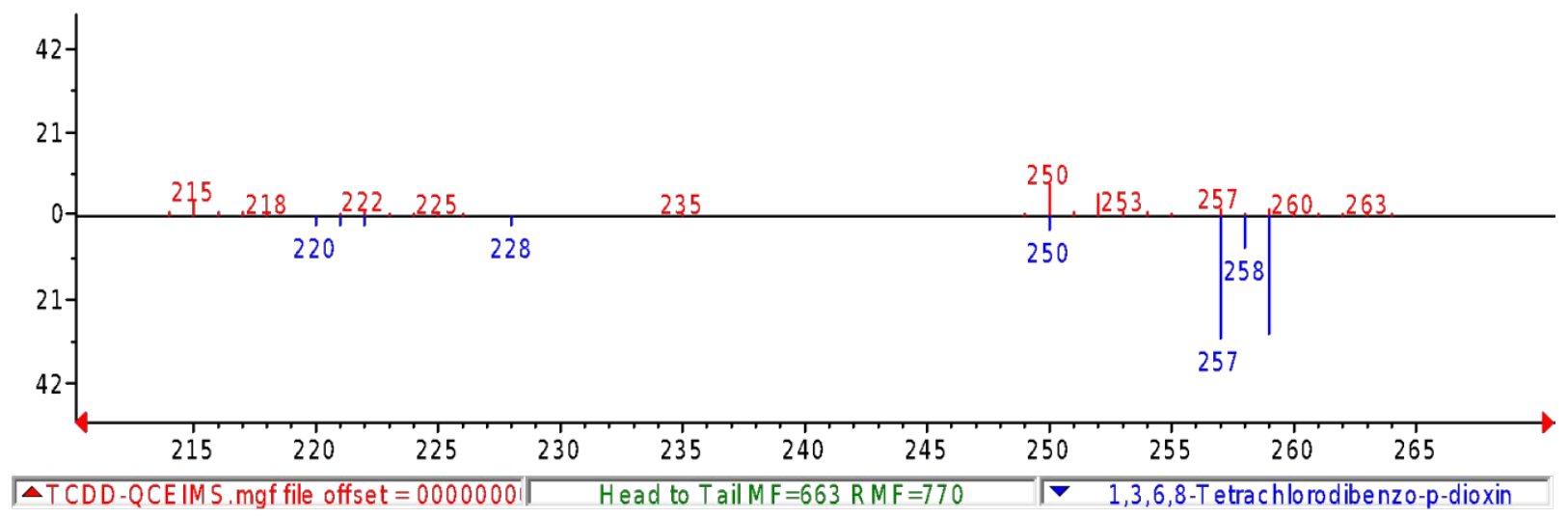

Figure S-19. QCEIMS spectrum (top, red) and CFM-EI spectrum (middle, red) compared to NIST Database EI spectrum (blue) of 2,3,7,8-tetrachlorodibenzodioxin (TCDD). Bottom: close-up of the $m / z$ 215-265 region of the QCEIMS (red) and NIST Database EI (blue) spectra, showing the presence of [M-COCl] ${ }^{+}$at $m / z 257$.
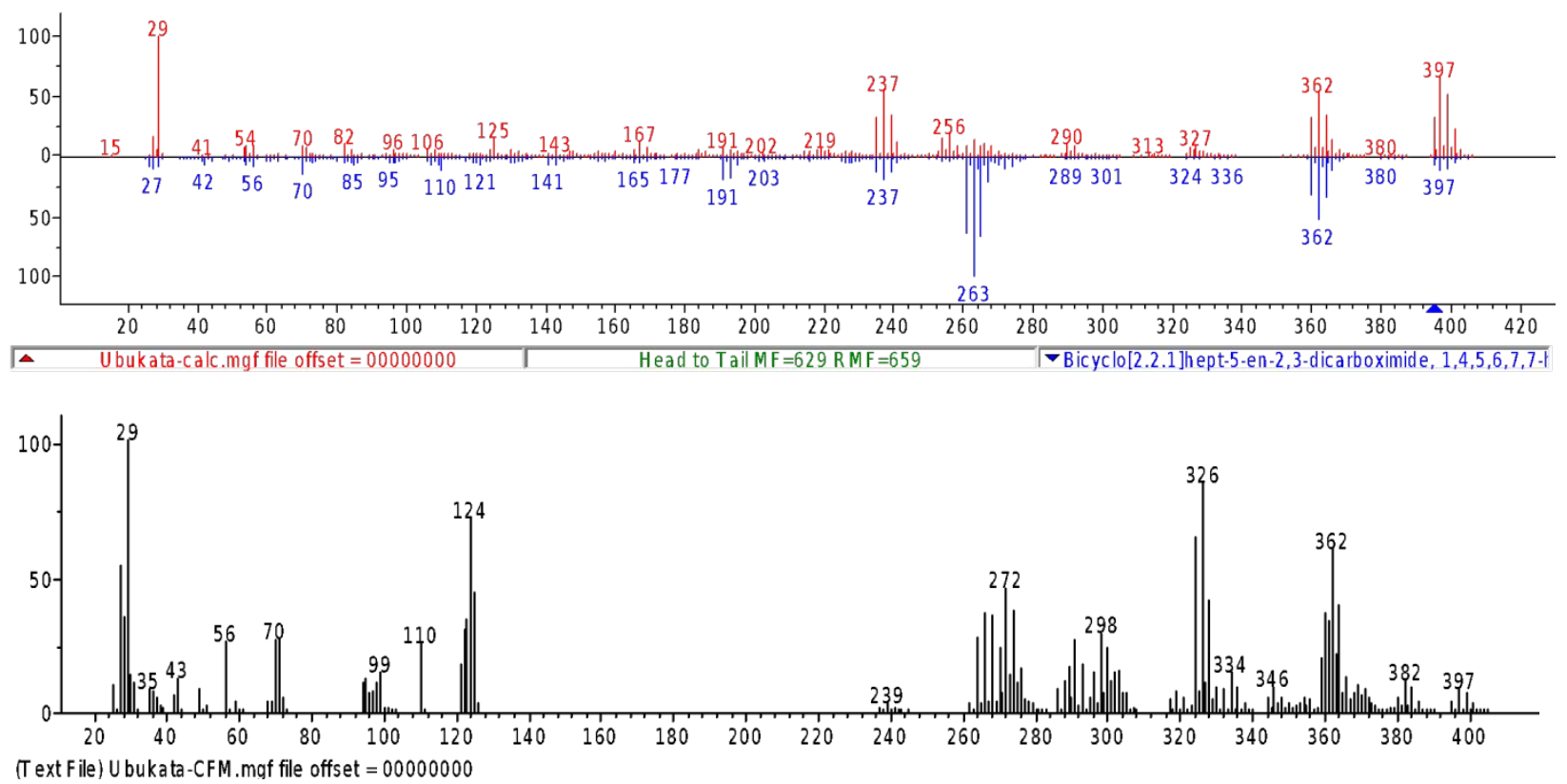

Figure S-20. Top: QCEIMS spectrum (red) compared to NIST Database EI spectrum (blue) of 1,4,5,6,7,7hexachloro-N-ethyl-bicyclo [2,2,1]hept-5-en-2,3-dicarboximide. Bottom: CFM-EI spectrum of 1,4,5,6,7,7hexachloro-N-ethyl-bicyclo $[2,2,1]$ hept-5-en-2,3-dicarboximide. 

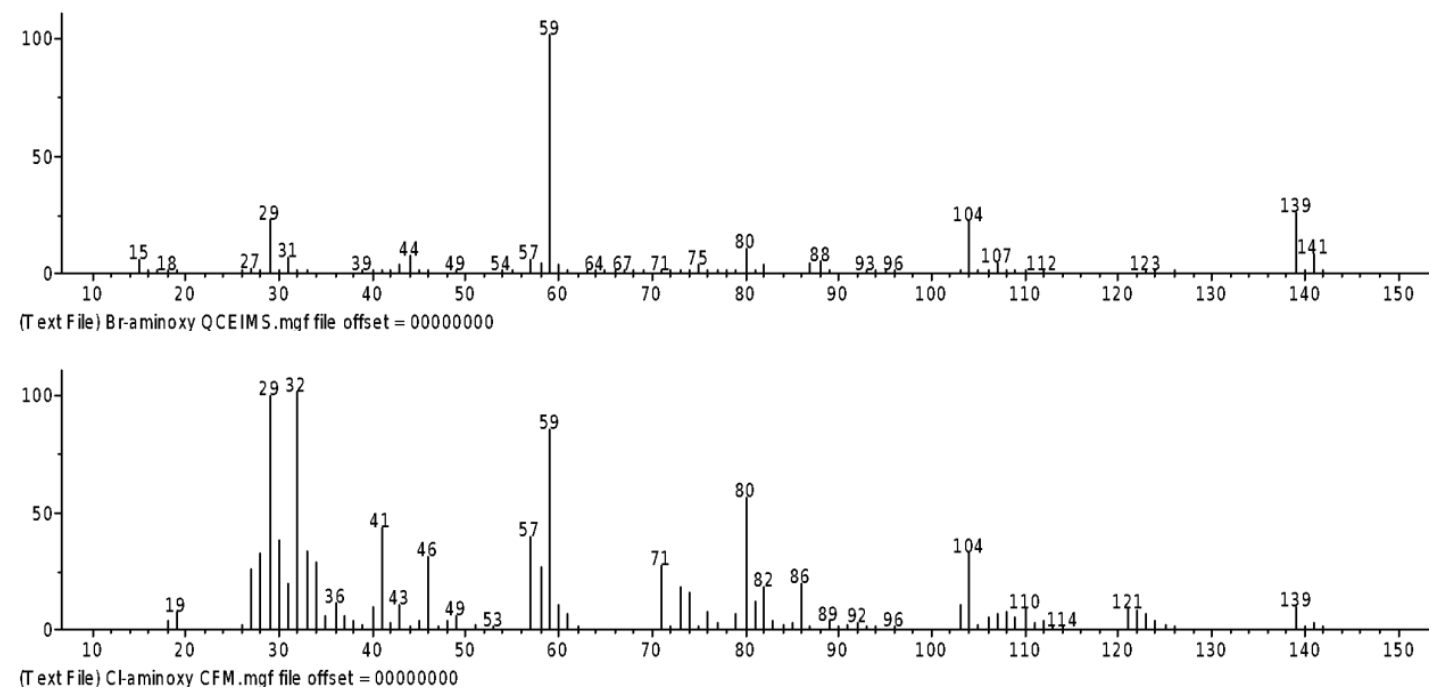

Figure S-21. QCEIMS spectrum (top) and CFM-EI spectrum (bottom) of 1-aminoxy-1-chloro butan-2-ol.
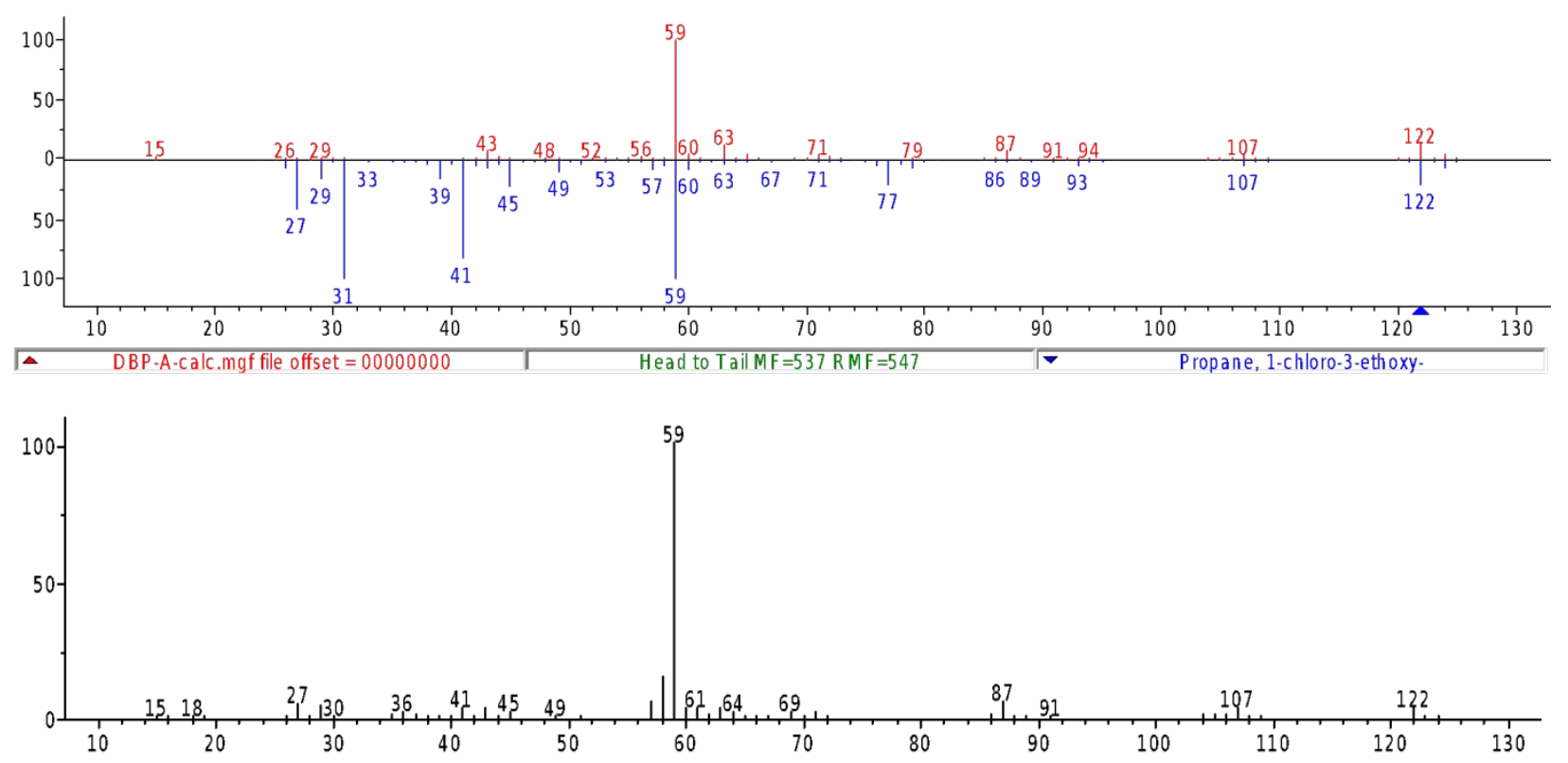

(T ext F ile) Chloroalc ohol CFM -ID . maf file offset $=00000000$

Figure S-22. Top: QCEIMS spectrum (red) compared to NIST Database EI spectrum (blue) of 3-chloro-2methylbutan-2-ol. Bottom: CFM-EI spectrum of 3-chloro-2-methyl butan-2-ol. 

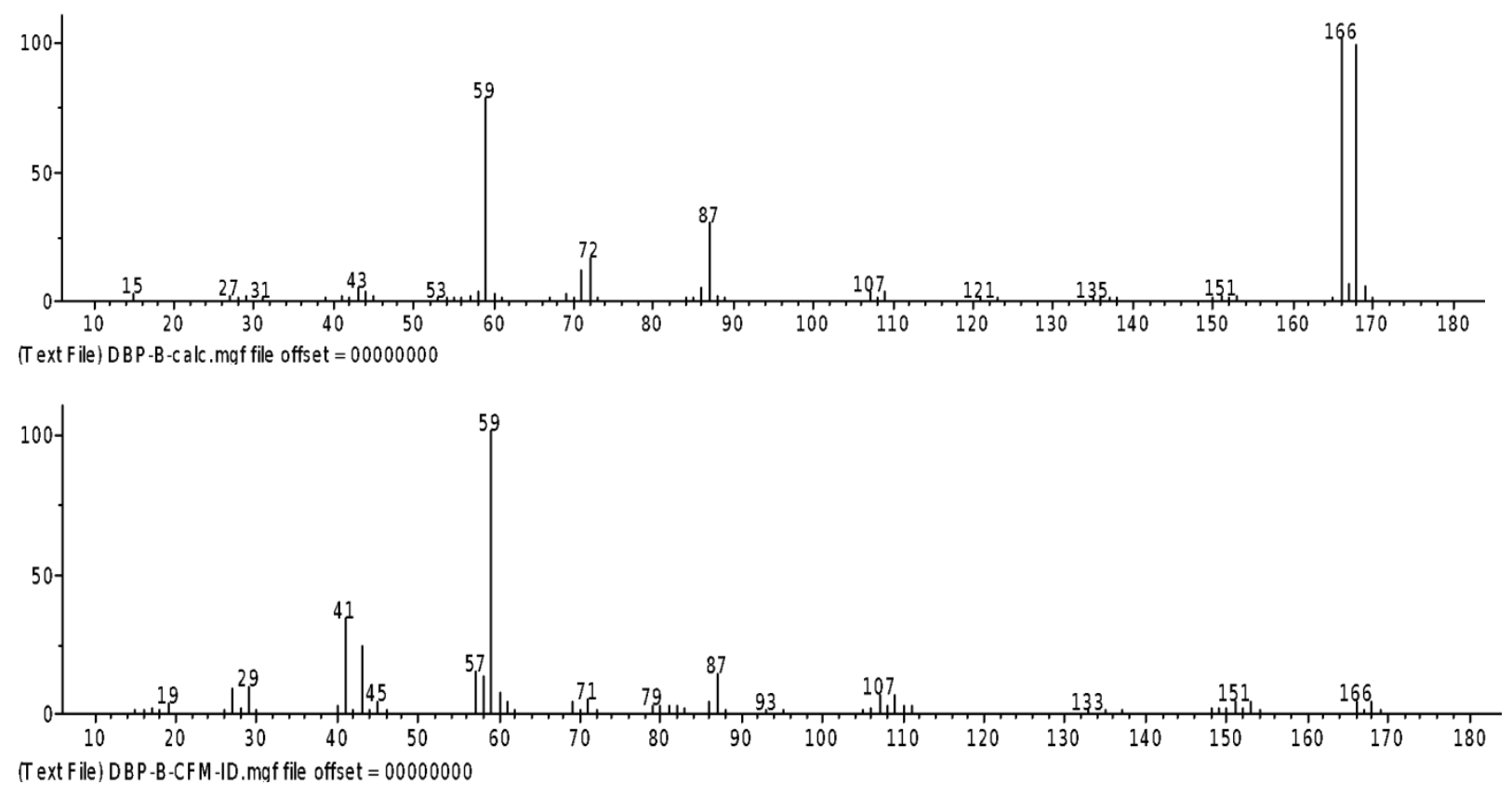

Figure S-23. QCEIMS spectrum (top) and CFM-EI (bottom) spectrum of 3-bromo-2-methylbutan-2-ol.
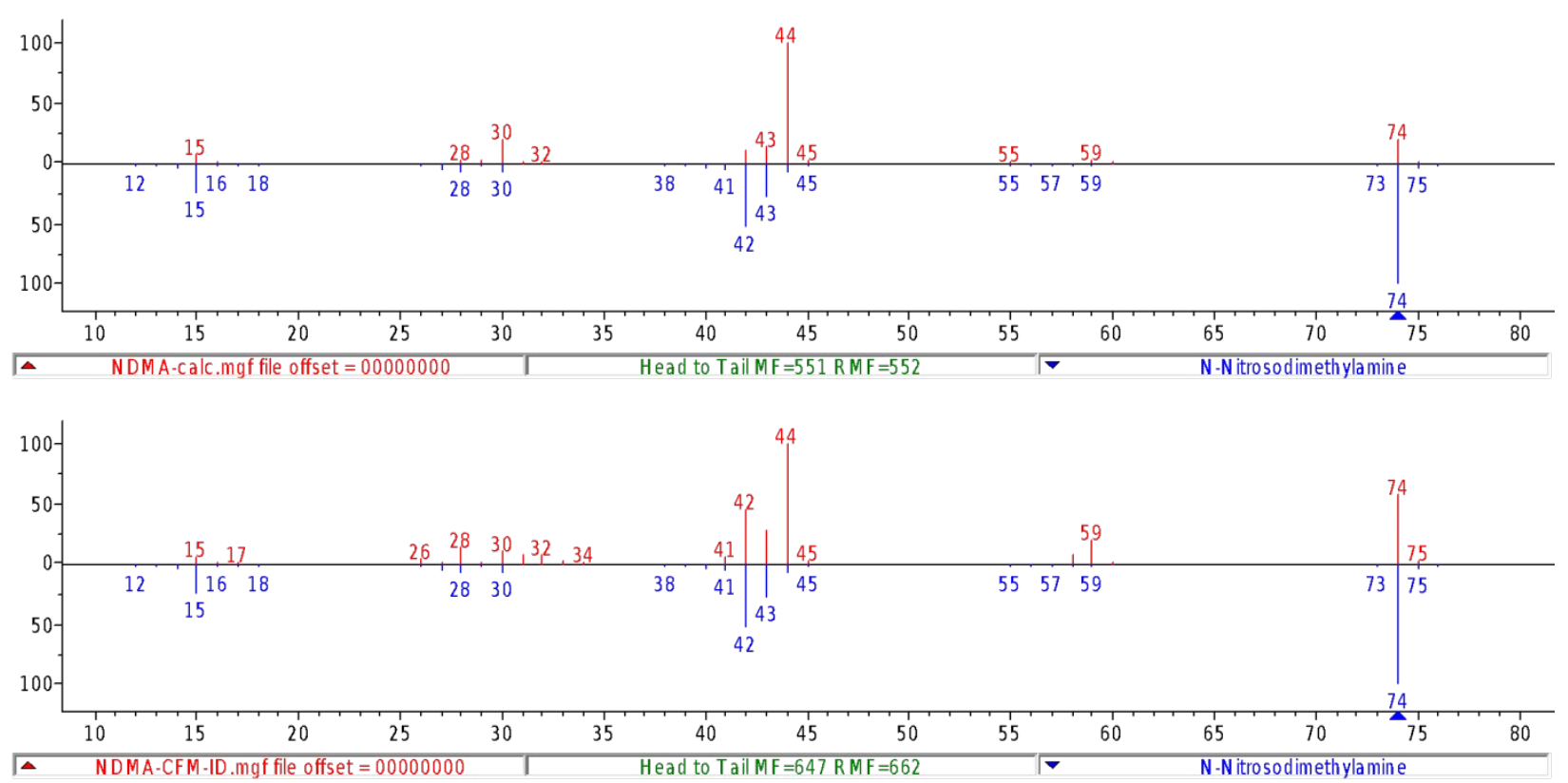

Figure S-24. QCEIMS spectrum (top, red) and CFM-EI spectrum (bottom, red) compared to NIST Database EI spectrum (blue) of n-nitrosodimethylamine (NDMA). 


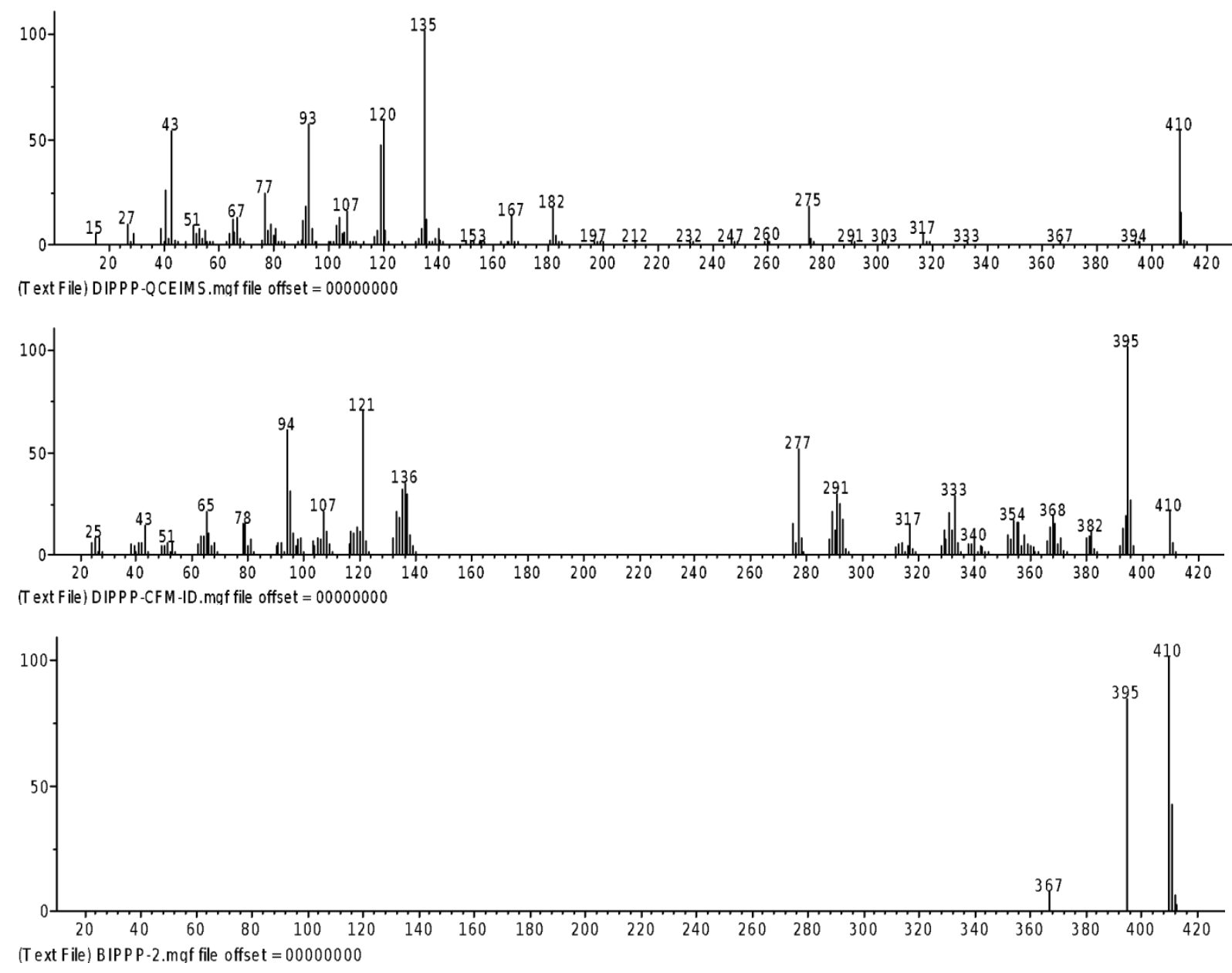

Figure S-25. QCEIMS spectrum (top), CFM-EI spectrum (center), and experimental CID spectrum (bottom) of bis(isopropylphenyl) phenyl phosphate (BIPPP).
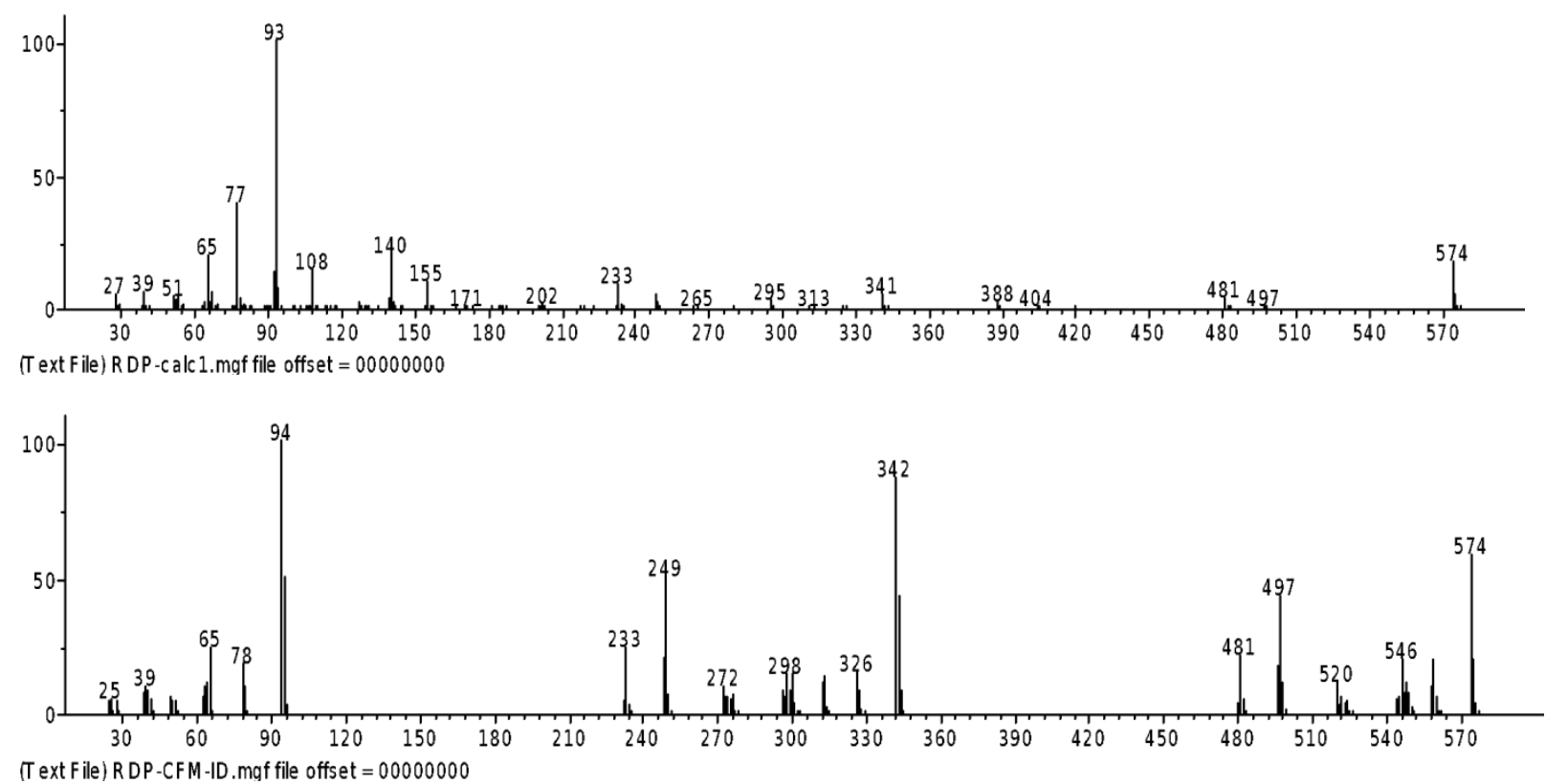


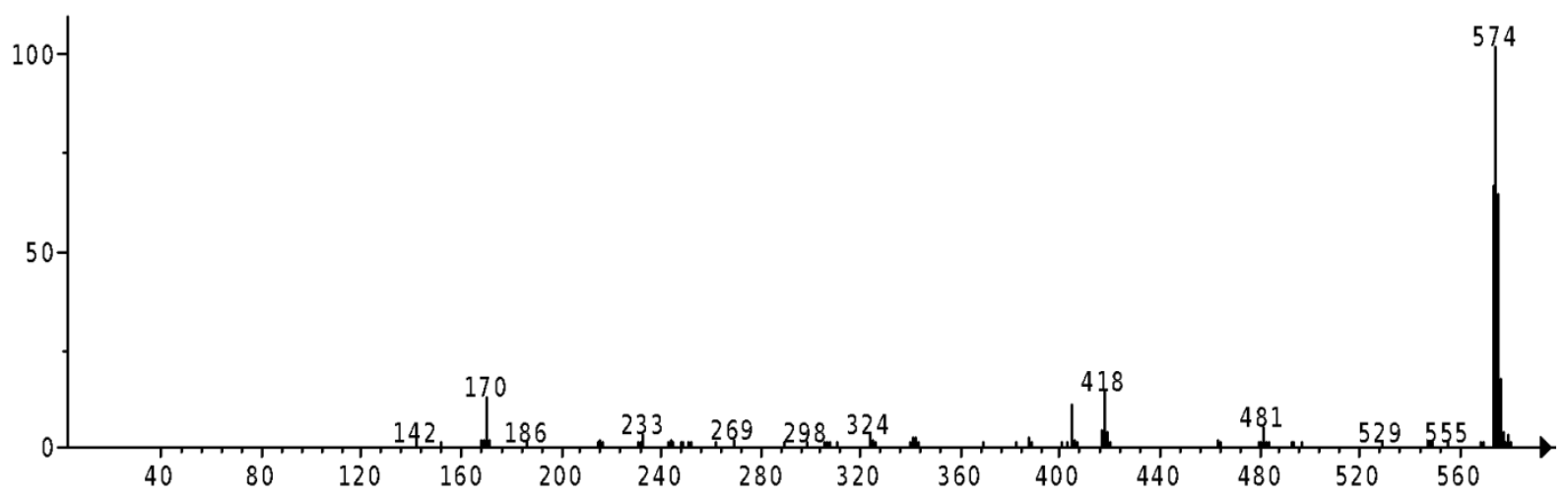

(T ext File) RDP-SQDIA-redo. maf file offset $=00000000$

Figure S-26. QCEIMS spectrum (top) and CFM-EI spectrum (bottom) of resorcinol bis(diphenyl phosphate) (RDP).

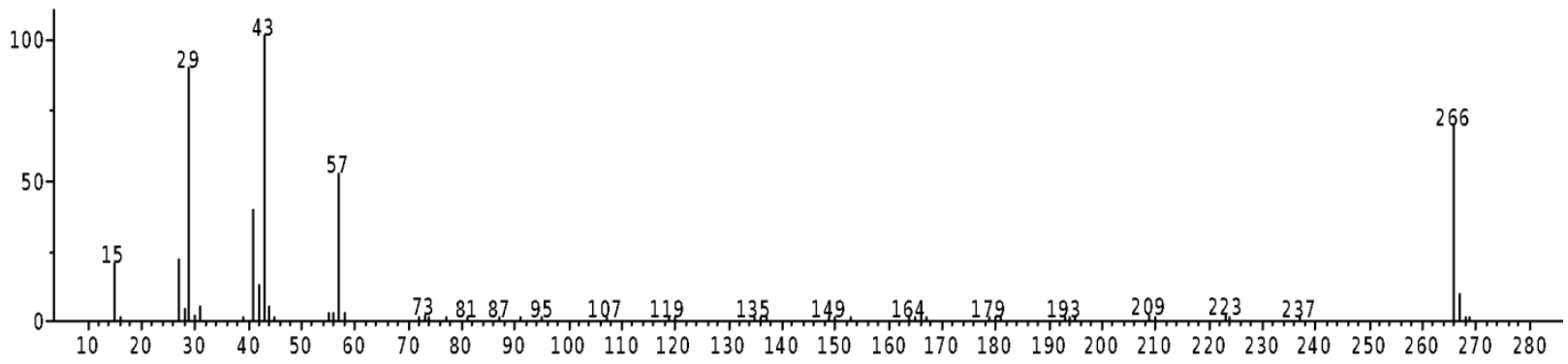
$(T$ ext File $)$ TBP-QCEIM S. mgf file offset $=00000000$

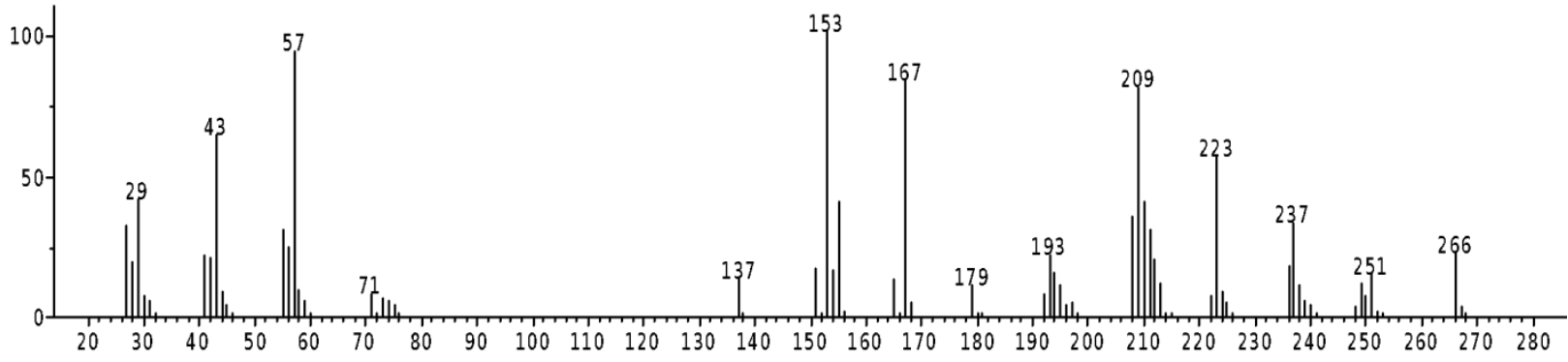
(T ext File) TBP-CFM .mgf file offset $=00000000$

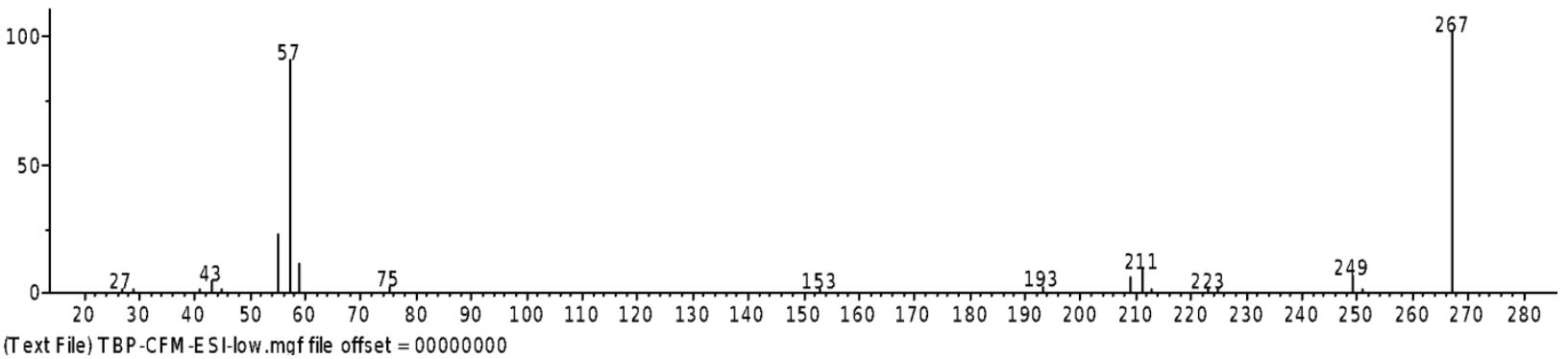

Figure S-27. QCEIMS spectrum (top), CFM-EI spectrum (center), and CFM-ESI spectrum calculated at low energy (bottom) of tributyl phosphate (TBP). The CFM-ESI spectrum has an $[\mathrm{M}+\mathrm{H}]^{+}$pseudo-molecular ion. 

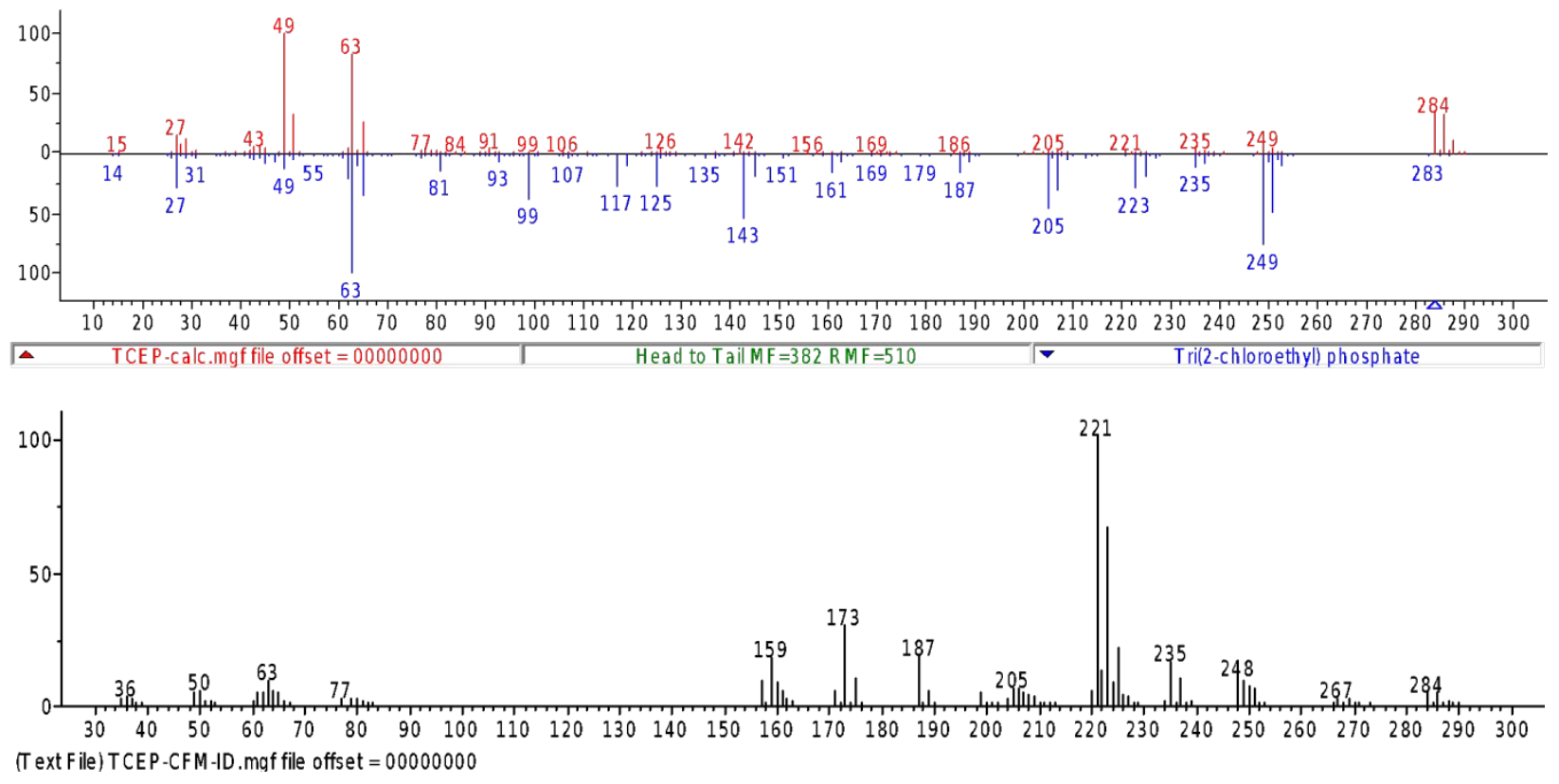

Figure S-28. Top: QCEIMS spectrum (red) compared to NIST Database EI spectrum (blue) of trichloroethyl phosphate (TCEP). Bottom: CFM-EI spectrum of TCEP. 

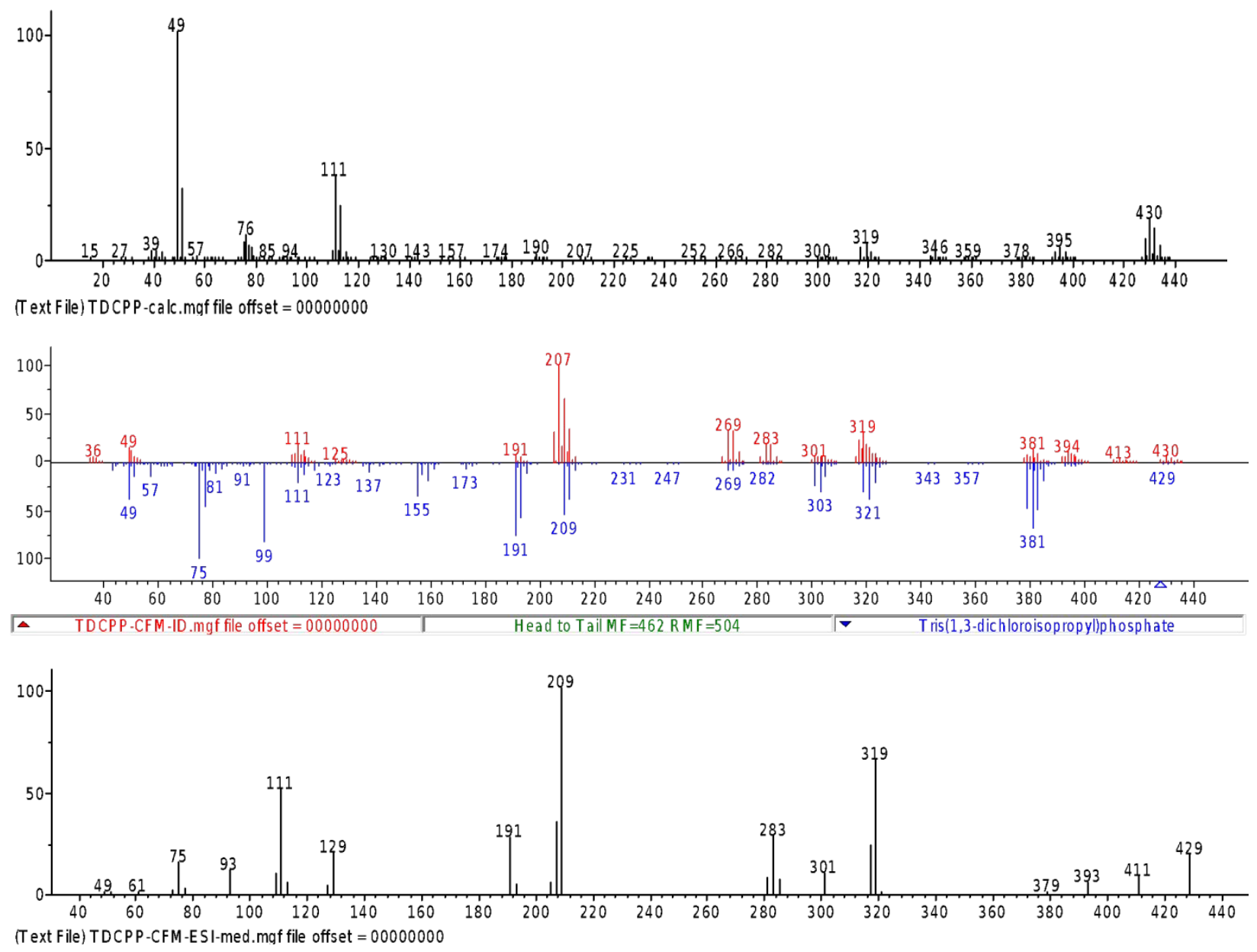

Figure S-29. Top: QCEIMS spectrum of tris(1,3-dichloro-2-propyl) phosphate (TDCPP). Center: CFM-EI spectrum (red) compared to NIST Database EI spectrum (blue) of TDCPP. Bottom: CFM-ESI spectrum calculated at medium energy of TDCPP. 

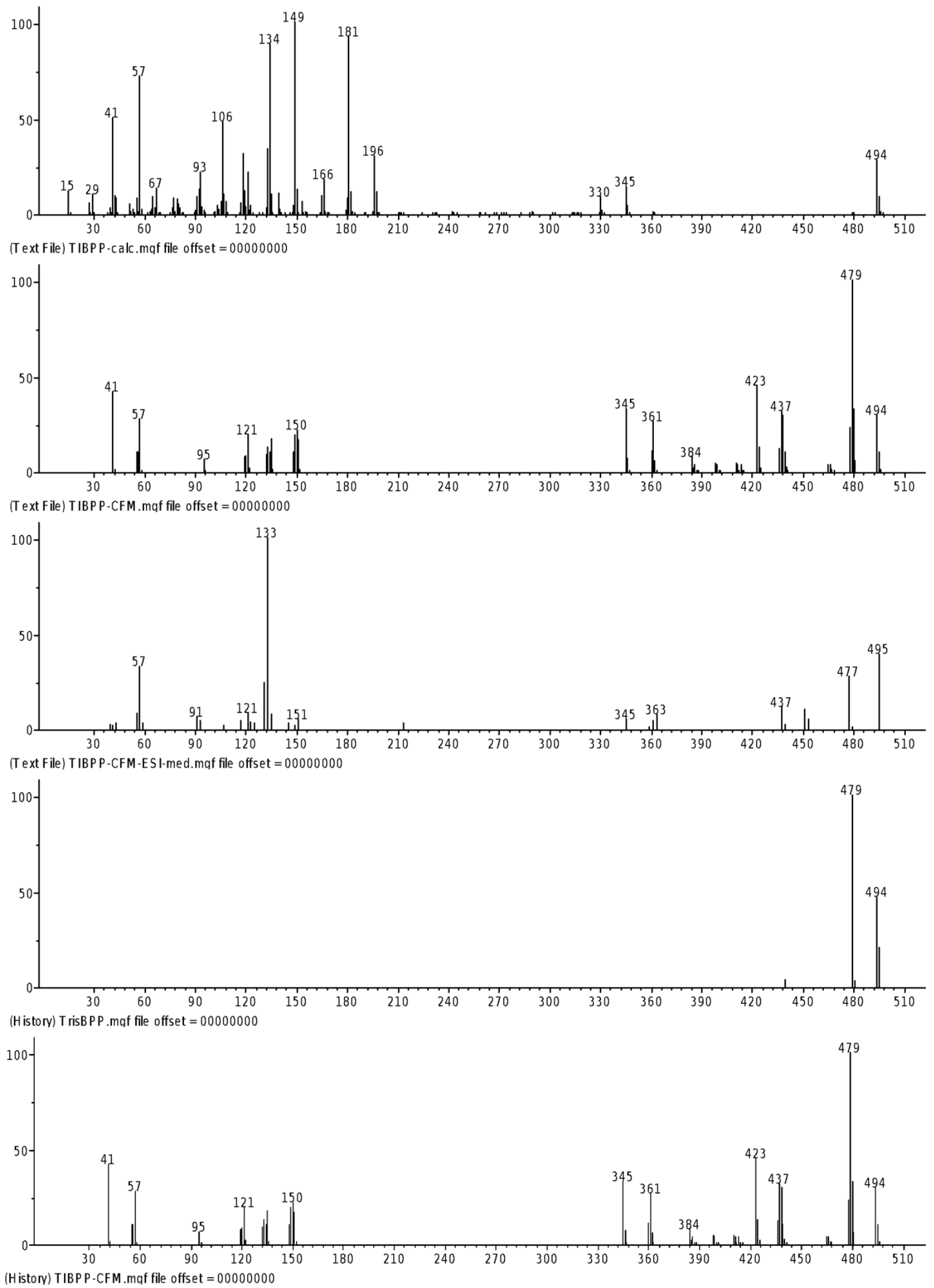

Figure S-30. A) QCEIMS spectrum, b) CFM-EI spectrum, c) CFM-ESI spectrum, d) experimental CID spectrum, and e) NIST database EI spectrum of tris(tert-butylphenyl) phosphate (TIBPP). 

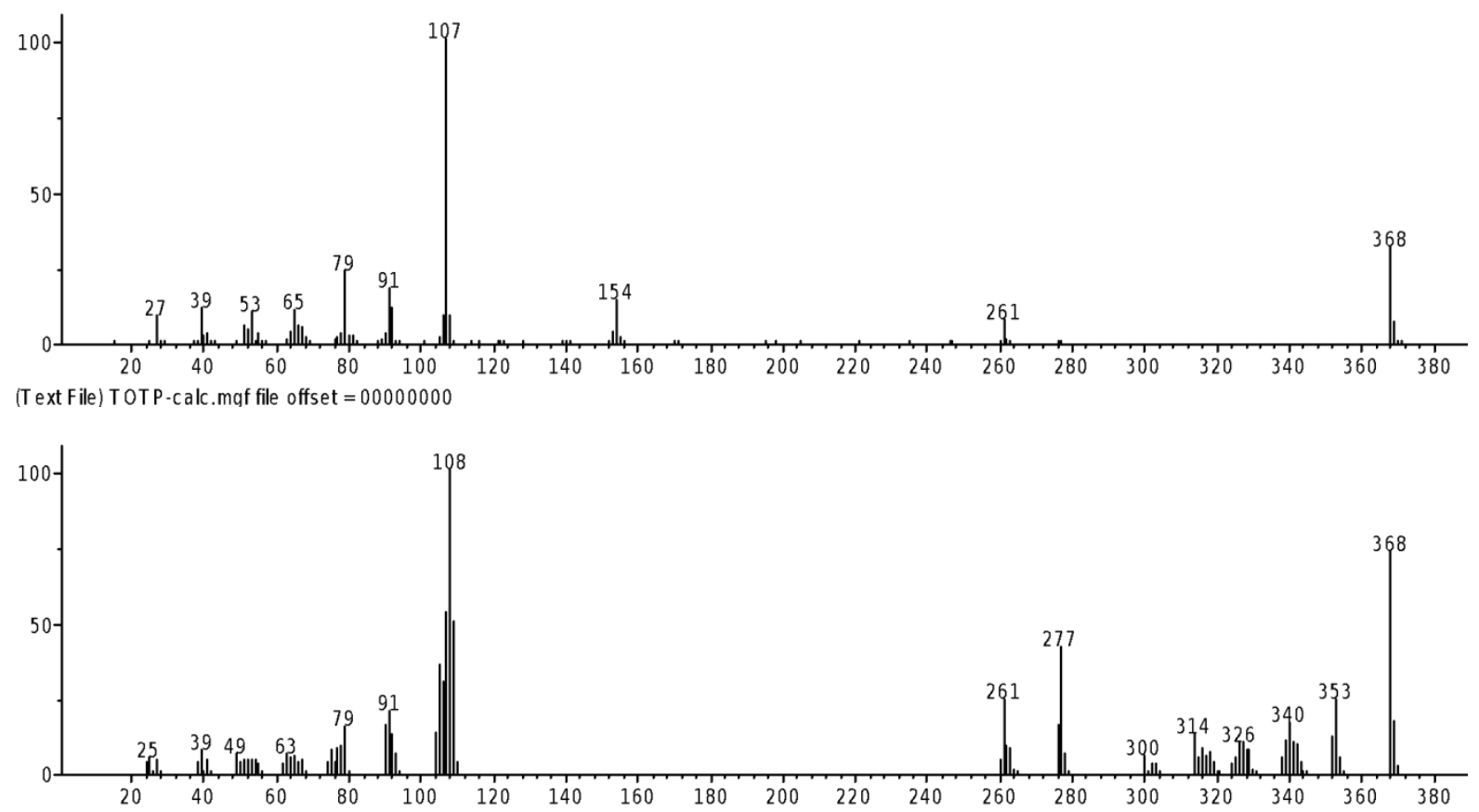

(T ext File) TCP-CFM-ID . maf file offset $=00000000$

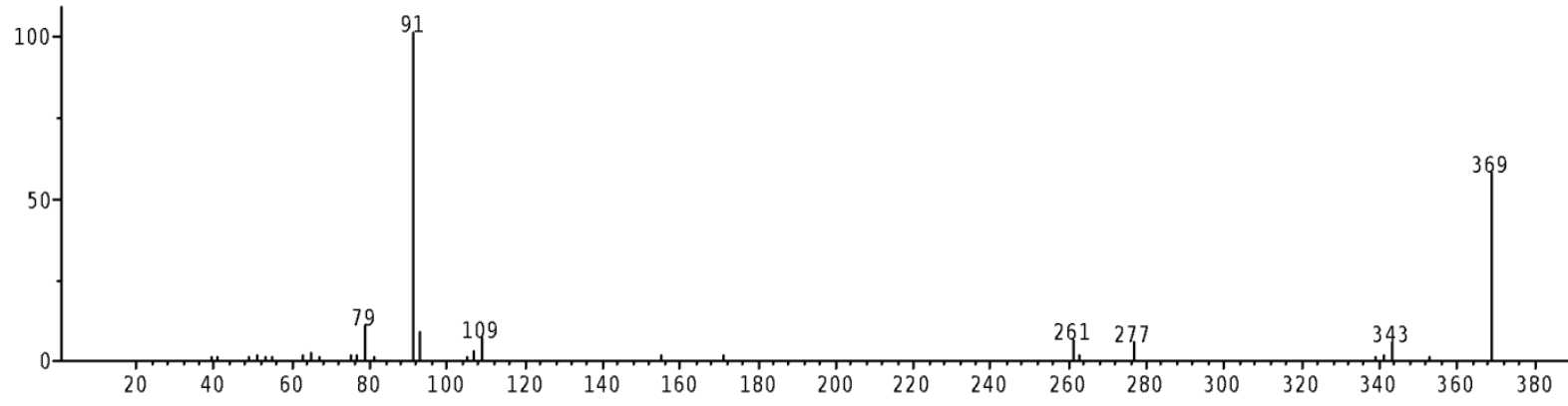
(T ext File) TCP-CFM-ESI-medE. mqf file offset $=00000000$

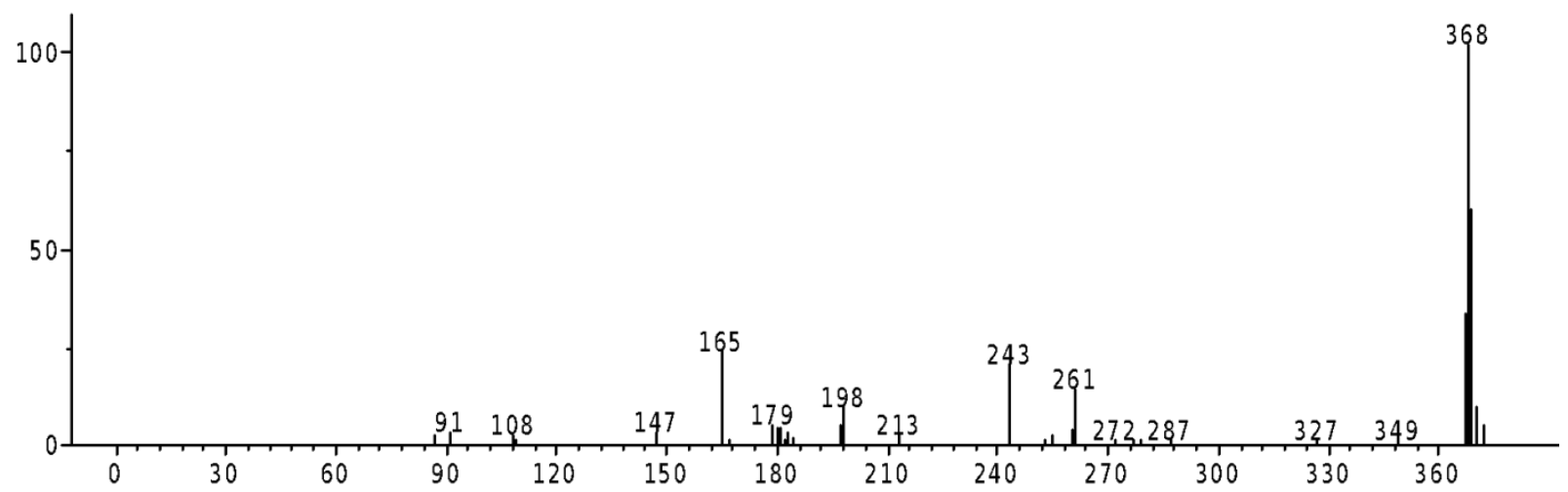

(T ext File) TCP -4 . maf file offset $=00000000$ 


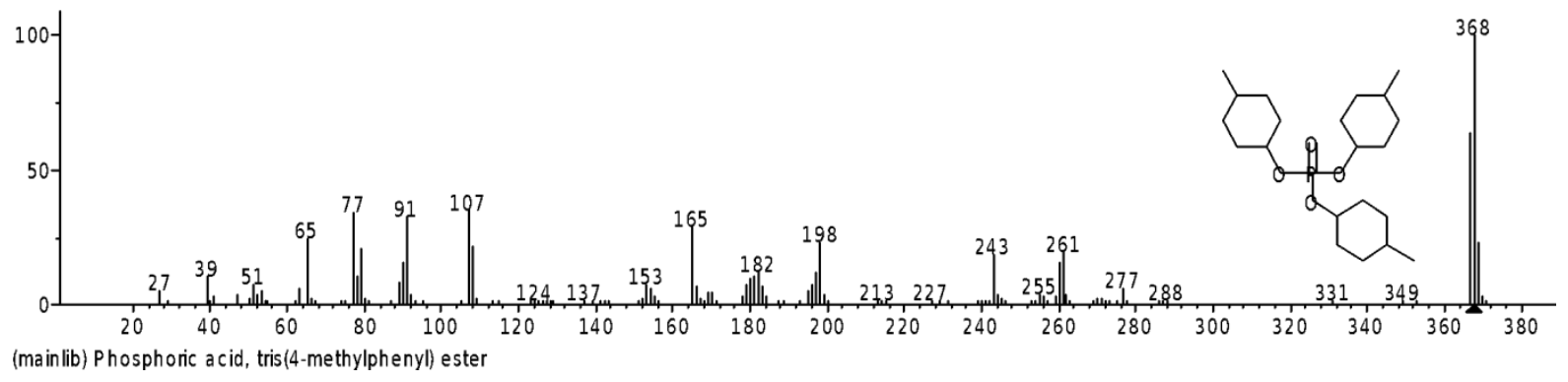

Figure S-31. A) QCEIMS spectrum, b) CFM-EI spectrum, c) CFM-ESI spectrum, d) experimental CID spectrum, and e) NIST database EI spectrum of tricresyl phosphate (TCP).
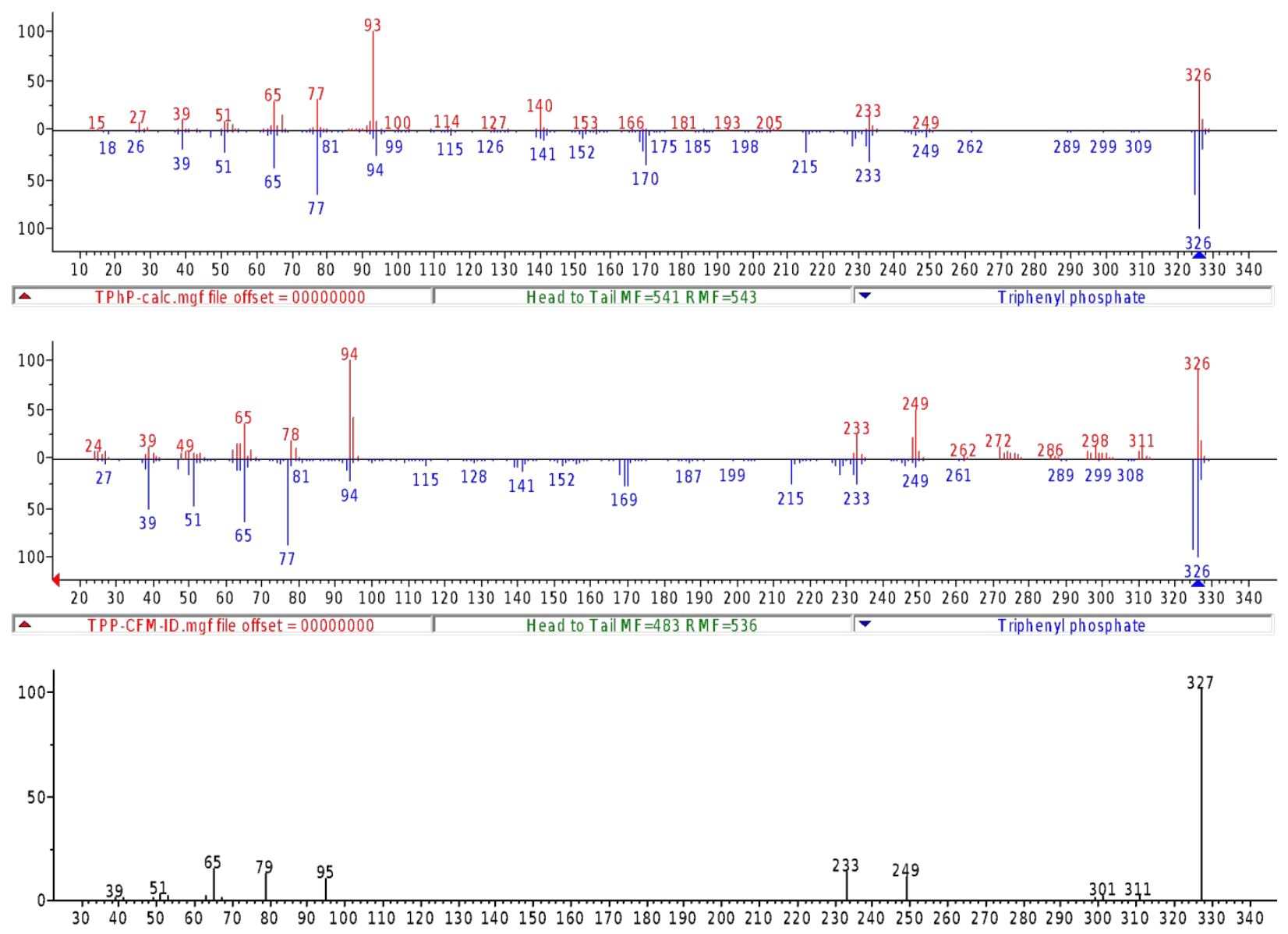
(T ext File) TPP-CFM-E SI-med. mgf file offset $=00000000$

Figure S-32. QCEIMS spectrum (top, red) and CFM-EI spectrum (center, red) compared to NIST Database EI spectrum (blue) of triphenyl phosphate (TPhP). Bottom: CFM-ESI spectrum of TPP. The spectrum was calculated at medium energy using the adduct $[\mathrm{M}+\mathrm{H}]^{+}$. 


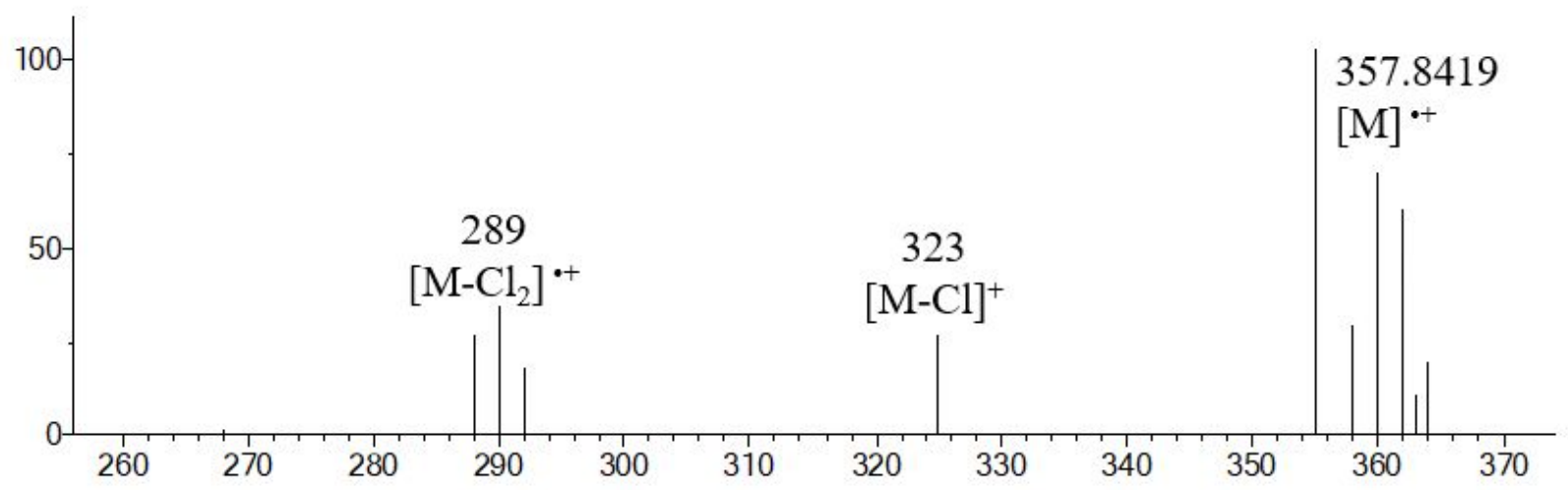

Figure S-33. SQDIA spectrum of hexachlorobiphenyl, showing an example of isotope peaks filtered out during spectral deconvolution.

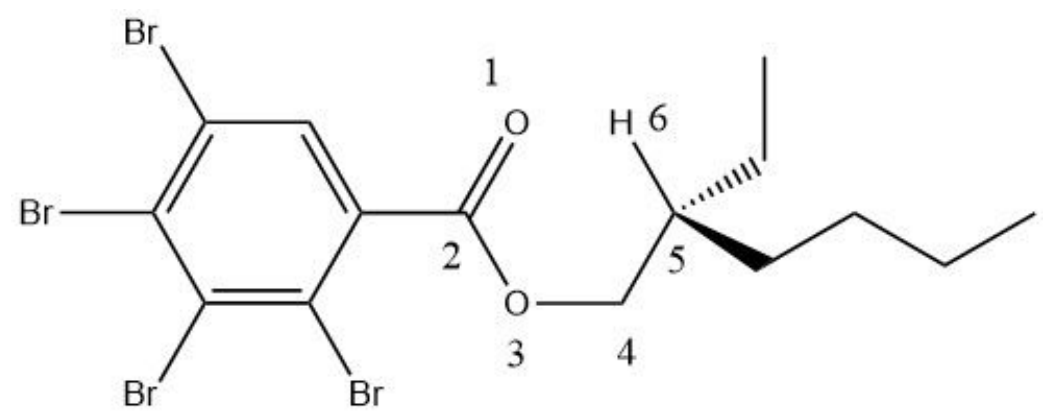

Figure S-34. Structure of EH-TBB modified to enable McLafferty rearrangement. The dihedral angle between atoms $3,4,5$, and 6 was modified such that all numbered atoms lie in the same plane. 


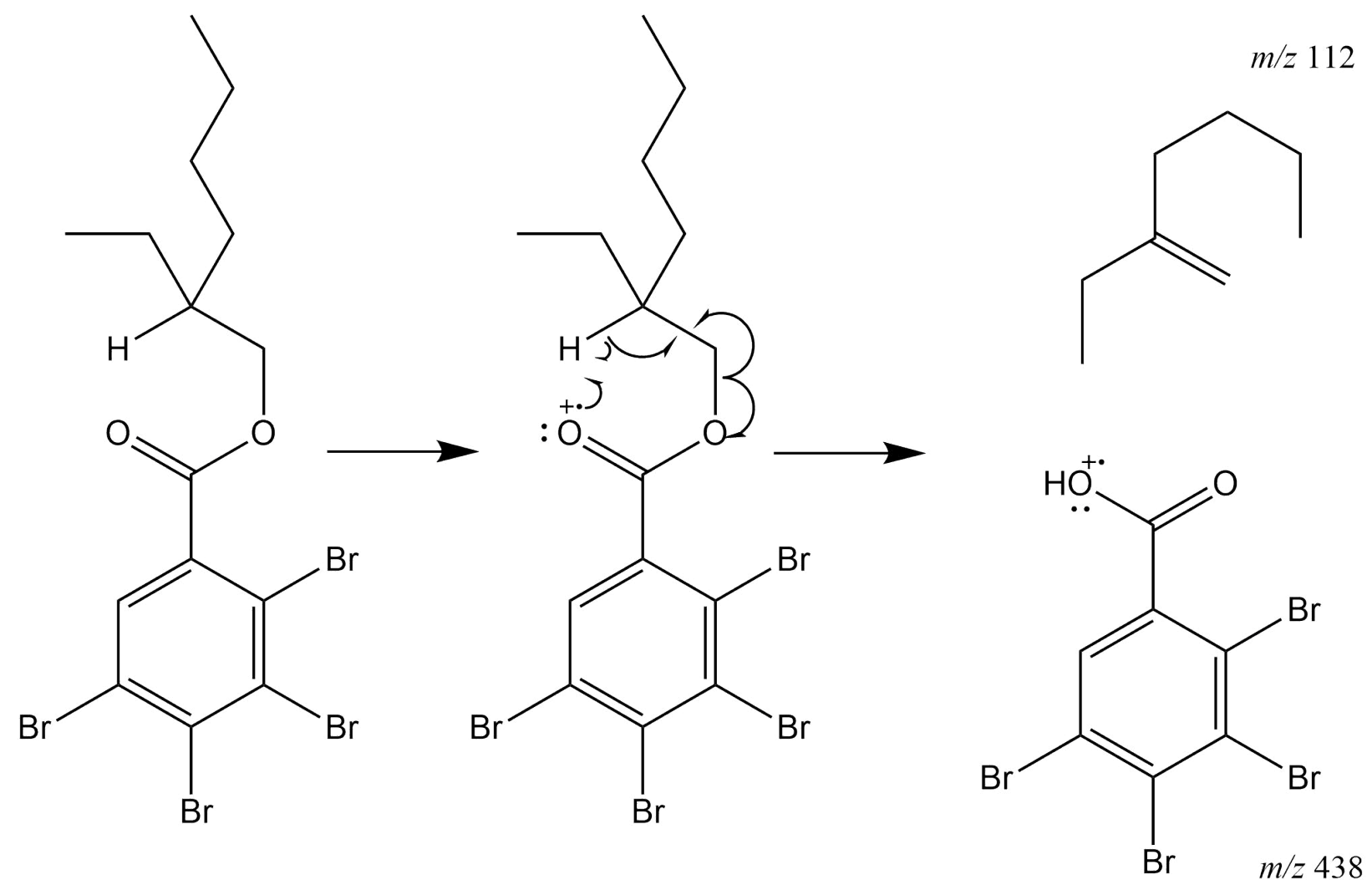

Figure S-35. Proposed mechanism of the 1,5-hydrogen shift (McLafferty rearrangement) observed in EH-TBB. Fragment mass-to-charge ratios indicated are the intensoid peaks, not monoisotopic masses.
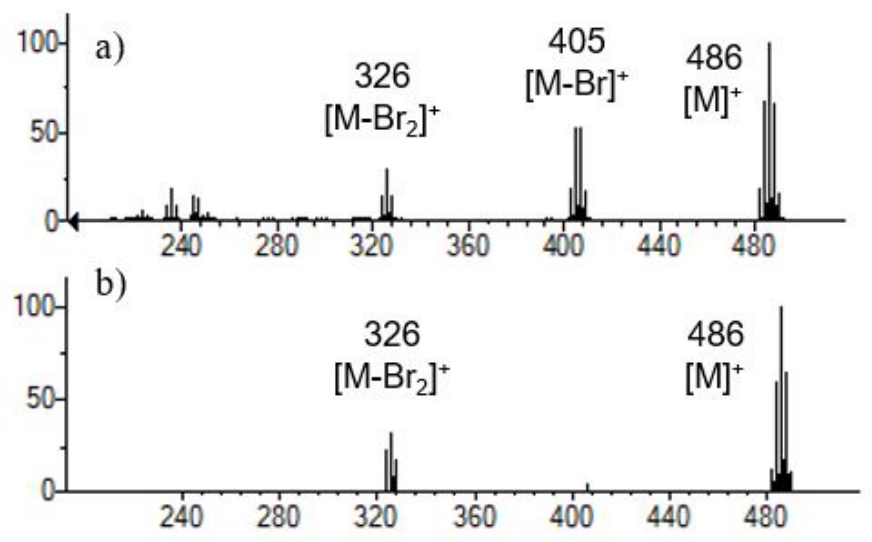

Figure S-36. A) EI mass spectrum of BDE-47 calculated by QCEIMS and b) experimental CID spectrum of BDE47. 

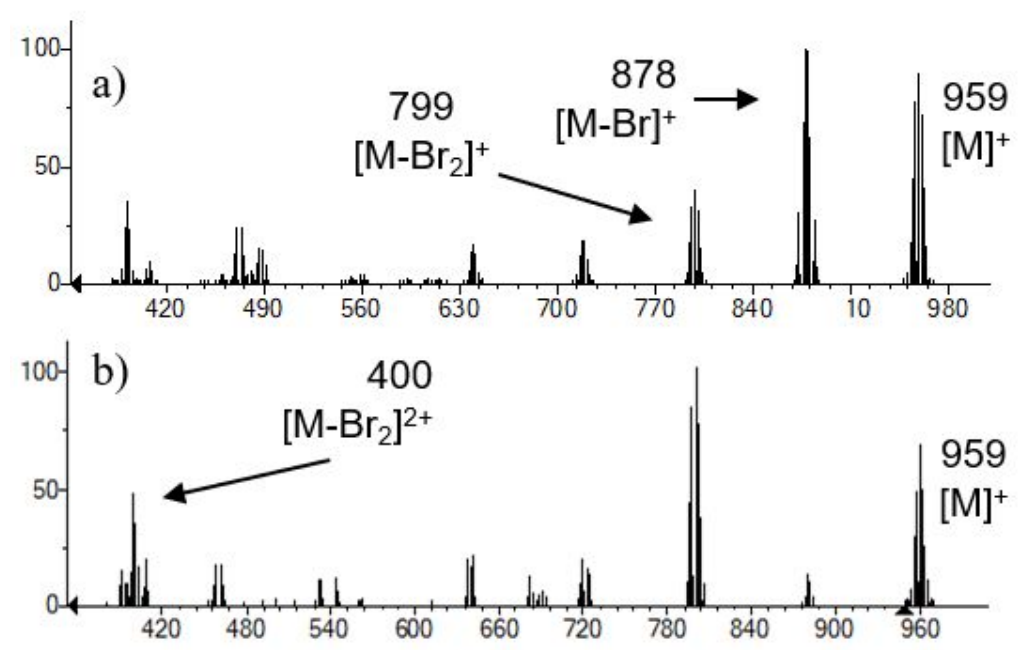

Figure S-37. A) EI mass spectrum of BDE-209 calculated by QCEIMS and B) experimental EI spectrum of BDE209. The masses in the NIST library spectrum of BDE-209 are one mass unit higher than those shown here because of a difference in calculating nominal masses. ${ }^{1}$

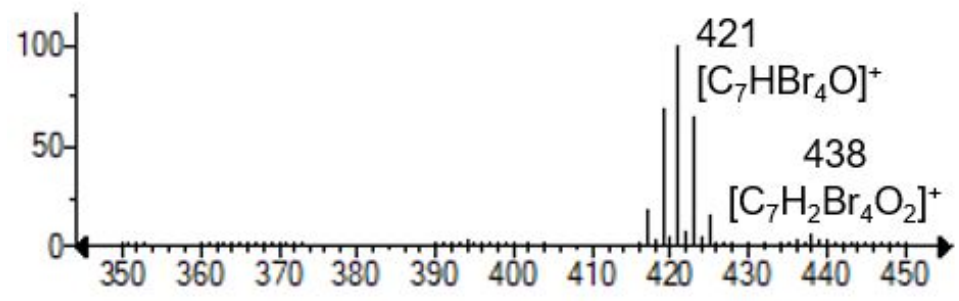

Figure S-38. EI mass spectrum of EH-TBB calculated by CFM-EI. 


\section{Tables}

Table S-1. Source of input structure and optimization of compounds modelled by QCEIMS.

\begin{tabular}{|c|c|c|c|}
\hline Name & Class & Source $^{\mathrm{a}}$ & Optimized? ${ }^{b}$ \\
\hline $\begin{array}{l}2,2^{\prime}, 4,4^{\prime}, 5,5^{\prime}-\text { Hexabromodiphenyl } \\
\text { ether (BDE-153) }\end{array}$ & $\mathrm{Br}$ & Download & No \\
\hline $\begin{array}{l}2,2^{\prime}, 3,4,4^{\prime}, 5^{\prime}, 6- \\
\text { Heptabromodiphenyl ether (BDE- } \\
183)\end{array}$ & $\mathrm{Br}$ & Avogadro & Yes \\
\hline $\begin{array}{l}\text { Decabromodiphenyl ether (BDE- } \\
\text { 209) }\end{array}$ & $\mathrm{Br}$ & Download & Yes \\
\hline $\begin{array}{l}2,2^{\prime}, 4,4^{\prime} \text {-Tetrabromodiphenyl } \\
\text { ether (BDE-47) }\end{array}$ & $\mathrm{Br}$ & Download & Yes \\
\hline $\begin{array}{l}3,3^{\prime}, 4,4^{\prime} \text {-Tetrabromodiphenyl } \\
\text { ether (BDE-77) }\end{array}$ & $\mathrm{Br}$ & Download & Yes \\
\hline $\begin{array}{l}\text { 1,2-Bis(2,4,6-tribromophenoxy) } \\
\text { ethane (BTBPE) }\end{array}$ & $\mathrm{Br}$ & Download & No \\
\hline Hexabromobenzene (HBB) & $\mathrm{Br}$ & Download & No \\
\hline $\begin{array}{l}\text { 2-Ethylhexyl-2,3,4,5- } \\
\text { tetrabromobenzoate (EH-TBB) }\end{array}$ & $\mathrm{Br}$ & Download & Yes \\
\hline Tetrabromobisphenol A (TBBPA) & $\mathrm{Br}$ & Download & No \\
\hline $\begin{array}{l}\text { Bis(2-ethylhexyl)-2,3,4,5- } \\
\text { tetrabromophthalate (BEH-TEBP) }\end{array}$ & $\mathrm{Br}$ & Download & Yes \\
\hline $\begin{array}{l}\text { 3,3',5-Tribromodiphenyl ether } \\
\text { (BDE-36) }\end{array}$ & $\mathrm{Br}$ & Download & No \\
\hline $\begin{array}{l}\text { 1,8-dibromo-3,6-dichloro } \\
\text { carbazole }\end{array}$ & $\mathrm{Cl} / \mathrm{Br}$ & Download & Yes \\
\hline & & & \\
\hline
\end{tabular}




\begin{tabular}{|c|c|c|c|}
\hline Name & Class & Source ${ }^{a}$ & Optimized? \\
\hline $\begin{array}{l}\text { Dichlorodiphenyldichloroethylene } \\
\text { (DDE) }\end{array}$ & $\mathrm{Cl}$ & Download & Yes \\
\hline $\begin{array}{l}\text { Dichlorodiphenyltrichloroethane } \\
\text { (DDT) }\end{array}$ & $\mathrm{Cl}$ & Download & Yes \\
\hline Dechlorane Plus (DP) & $\mathrm{Cl}$ & Avogadro & Yes \\
\hline $\begin{array}{l}\text { 4-OH-2',3,3', } 4^{\prime}, 5,5^{\prime}- \\
\text { hexachlorobiphenyl }\end{array}$ & $\mathrm{Cl}$ & Avogadro & Yes \\
\hline $\begin{array}{l}3,3^{\prime}, 4,4^{\prime}, 5,5^{\prime}-\text { Hexachlorobiphenyl } \\
(\text { PCB-169) }\end{array}$ & $\mathrm{Cl}$ & Download & No \\
\hline $\begin{array}{l}\text { 2,4,4',5,5'-Pentachlorobiphenyl } \\
\text { (PCB-118) }\end{array}$ & $\mathrm{Cl}$ & Download & Yes \\
\hline $\begin{array}{l}\text { 2,3,7,8-Tetrachlorodibenzodioxin } \\
\text { (TCDD) }\end{array}$ & $\mathrm{Cl}$ & Download & No \\
\hline $\begin{array}{l}\text { 2,4,4',5-Tetrachlorobiphenyl } \\
\text { (PCB-74) }\end{array}$ & $\mathrm{Cl}$ & Download & No \\
\hline $\begin{array}{l}\text { 2,4,4'-Trichlorobiphenyl (PCB- } \\
\text { 28) }\end{array}$ & $\mathrm{Cl}$ & Download & No \\
\hline $\begin{array}{l}\text { 1,4,5,6,7,7-hexachloro-N-ethyl- } \\
\text { bicyclo }[2,2,1] \text { hept-5-en-2,3- } \\
\text { dicarboximide }\end{array}$ & $\mathrm{Cl}$ & Avogadro & Yes \\
\hline 1-Aminoxy-1-bromobutan-2-ol & DBP & Download & No \\
\hline 1-Aminoxy-1-chlorobutan-2-ol & DBP & Download & Yes \\
\hline 3-chloro-2-methylbutan-2-ol & DBP & Download & Yes \\
\hline 3-bromo-2-methylbutan-2-ol & DBP & Avogadro & Yes \\
\hline
\end{tabular}




\begin{tabular}{|l|l|l|l|}
\hline Name & Class & Source $^{\text {a }}$ & Optimized? \\
\hline $\begin{array}{l}\text { N-Nitrosodimethylamine } \\
\text { (NDMA) }\end{array}$ & DBP & Download & Yes \\
\hline $\begin{array}{l}\text { Bis(isopropylphenyl) phenyl } \\
\text { phosphate (BIPPP) }\end{array}$ & P & Download & No \\
\hline $\begin{array}{l}\text { Resorcinol bis(diphenyl } \\
\text { phosphate) (RDP) }\end{array}$ & P & Avogadro & Yes \\
\hline $\begin{array}{l}\text { Tributyl phosphate (TBP) } \\
\text { Trichloroethyl phosphate (TCEP) }\end{array}$ & P & Download & Yes \\
\hline $\begin{array}{l}\text { Tris(1,3-dichloro-2-propyl) } \\
\text { phosphate (TDCPP) }\end{array}$ & P & Download & Yes \\
\hline $\begin{array}{l}\text { Tris(isobutylphenyl) phosphate } \\
\text { (TIBPP) }\end{array}$ & P & Download & No \\
\hline $\begin{array}{l}\text { Tricresyl phosphate (TCP) } \\
\text { Triphenyl phosphate (TPhP) }\end{array}$ & P & Download & Yes \\
\hline
\end{tabular}

a Structures available on ChemSpider ${ }^{5}$ or PubChem ${ }^{6}$ were obtained as .mol files (indicated as "Download"). The remainder were built using Avogadro (version 1.2.0) ${ }^{7}$ and optimized using the standard MMFF 94 force-field.

${ }^{\mathrm{b}}$ All structures built in Avogadro and most downloaded structures were further optimized using Gaussian $16^{8}$ at the B3LYP/6-311G (2d,d,p) level of theory. Eleven structures downloaded later in the study were not further optimized using Gaussian because previously downloaded structures had been found to be close to the optimized geometry and require little optimization, and small variations in input geometry (conformers and even isomers; see discussions on EH-TBB and the tetrabromodiphenyl ether isomers in the main body of the text) were found to have no effect on the mass spectrum produced. Therefore, it was assumed that the downloaded structures would produce an identical mass spectrum to the further optimized structures. 
Table S-2. Class distribution of spectra predicted using QCEIMS and CFM-EI in comparison with NIST Mass Spectral Database and experimental spectra.

\begin{tabular}{|l|r|r|r|r|r|r|r|r|}
\hline Class & \multicolumn{2}{|l|}{$\begin{array}{l}\text { Average match } \\
\text { factor }\end{array}$} & \multicolumn{2}{|l|}{ Average rank } & \multicolumn{2}{l|}{$\begin{array}{l}\text { Average } \\
\text { experimental peaks } \\
\text { matched }\end{array}$} & \multicolumn{2}{l|}{$\begin{array}{l}\text { Average percent of } \\
\text { experimental peaks } \\
\text { matched }\end{array}$} \\
\hline & QCEIMS & CFM-EI & QCEIMS & CFM-EI & QCEIMS & CFM-EI & QCEIMS & CFM-EI \\
\hline Br & 58 & 461 & 2 & 12 & 4 & 1 & 69 & 19 \\
\hline Cl & 723 & 545 & 1 & 1 & 4 & 2 & 78 & 21 \\
\hline DBP & 544 & 324 & 40 & 3 & 6 & 5 & 86 & 71 \\
\hline OPFR & 212 & 279 & 10 & 1 & 2 & 3 & 29 & 37 \\
\hline
\end{tabular}


Table S-3. Compounds used to assess suspect screening.

\begin{tabular}{|c|c|}
\hline Compounds in electronics waste dust sample & $\begin{array}{l}\text { Compounds included to test for false } \\
\text { positive results }\end{array}$ \\
\hline $2,2^{\prime}, 4,4^{\prime}, 5,5^{\prime}-$ Hexabromodiphenyl ether (BDE-153) & Dichlorodiphenyldichloroethylene (DDE) \\
\hline $\begin{array}{l}\text { 2,2',3,4,4',5',6-Heptabromodiphenyl ether (BDE- } \\
183)\end{array}$ & Dichlorodiphenyltrichloroethane (DDT) \\
\hline 2,2',4,4'-Tetrabromodiphenyl ether (BDE-47) & 4-OH-2',3,3',4',5,5'-Hexachlorobiphenyl \\
\hline 1 ,2-Bis(2,4,6-tribromophenoxy)ethane (BTBPE) & $\begin{array}{l}\text { 2,3,7,8-Tetrachlorodibenzodioxin } \\
(\mathrm{TCDD})^{3}\end{array}$ \\
\hline Hexabromobenzene (HBB) & 1-Aminoxy-1-chlorobutan-2-ol \\
\hline Tetrabromobisphenol A (TBBPA) & 3-Chloro-2-methylbutan-2-ol \\
\hline 3,3',5-Tribromodiphenyl ether (BDE-36) & 3-Bromo-2-methylbutan-2-ol \\
\hline 3,3',4,4',5,5'-Hexachlorobiphenyl (PCB-169) & N-Nitrosodimethylamine (NDMA) \\
\hline 2,4,4',5,5'-Pentachlorobiphenyl (PCB-118) & \\
\hline 2,4,4',5- Tetrachlorobiphenyl (PCB-74) & \\
\hline 2,4,4'-Trichlorobiphenyl (PCB-28) & \\
\hline Bis(isopropylphenyl) phenyl phosphate (BIPPP) & \\
\hline Resorcinol bis(diphenyl phosphate) (RDP) & \\
\hline Tributyl phosphate (TBP) & \\
\hline Tris(1,3-dichloro-2-propyl) phosphate (TDCPP) & \\
\hline Tris(isobutylphenyl) phosphate (TIBPP) & \\
\hline Tricresyl phosphate (TCP) & \\
\hline Triphenyl phosphate (TPhP) & \\
\hline
\end{tabular}




\begin{tabular}{|l|l|}
\hline Compounds in electronics waste dust sample & $\begin{array}{l}\text { Compounds included to test for false } \\
\text { positive results }\end{array}$ \\
\hline Dechlorane Plus (DP) & \\
\hline Decabromodiphenyl ether (BDE-209) & \\
\hline
\end{tabular}

\section{References}

1. Hites, R. A. Electron Impact and Electron Capture Negative Ionization Mass Spectra of Polybrominated Diphenyl Ethers and Methoxylated Polybrominated Diphenyl Ethers. Environ. Sci. Technol. 42, 2243-2252 (2008).

2. Grimme, S. Towards First Principles Calculation of Electron Impact Mass Spectra of Molecules. Angew. Chemie Int. Ed. 52, 6306-6312 (2013).

3. McLafferty, F. W. Aromatic Halogenated Compounds. Anal. Chem. 34, 16-25 (1962).

4. Hass, J. R., Friesen, M. D. \& Hoffman, M. K. The mass spectrometry of polychlorinated dibenzo-p-dioxins. Org. Mass Spectrom. 14, 9-16 (1979).

5. Pence, H. E. \& Williams, A. ChemSpider: An Online Chemical Information Resource. $J$. Chem. Educ. 87, 1123-1124 (2010).

6. Kim, S. et al. PubChem Substance and Compound databases. Nucleic Acids Res. 44, D1202-D1213 (2016).

7. Avogadro: an open-source molecular builder and visualization tool.

8. Frisch, M. J. et al. Gaussian 16, Revision A.03. (2016). 